TI 2015-082/III

Tinbergen Institute Discussion Paper

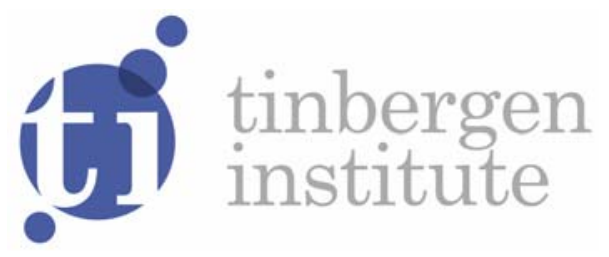

\title{
Why do Pit-Hours outlive the Pit?
}

\author{
Sait R. Ozturk \\ Michel van der Wel \\ Dick van Dijk
}


Tinbergen Institute is the graduate school and research institute in economics of Erasmus University Rotterdam, the University of Amsterdam and VU University Amsterdam.

More TI discussion papers can be downloaded at http://www.tinbergen.nl

Tinbergen Institute has two locations:

Tinbergen Institute Amsterdam

Gustav Mahlerplein 117

1082 MS Amsterdam

The Netherlands

Tel.: +31(0)205251600

Tinbergen Institute Rotterdam

Burg. Oudlaan 50

3062 PA Rotterdam

The Netherlands

Tel.: +31(0)10 4088900

Fax: $+31(0) 104089031$

Duisenberg school of finance is a collaboration of the Dutch financial sector and universities, with the ambition to support innovative research and offer top quality academic education in core areas of finance.

DSF research papers can be downloaded at: http://www.dsf.nl/

Duisenberg school of finance

Gustav Mahlerplein 117

1082 MS Amsterdam

The Netherlands

Tel.: +31(0)20 5258579 


\title{
Why do pit-hours outlive the pit?
}

\author{
Sait R. Ozturk ${ }^{(a, c)}$ Michel van der Wel ${ }^{(a, b, c, d)}$ Dick van Dijk $k^{(a, b, c)}$
}

July 3, 2015

(a) Econometric Institute, Erasmus School of Economics

(b) Erasmus Research Institute of Management

(c) Tinbergen Institute

(d) CREATES, Aarhus

Address for correspondence: Sait Ozturk, Econometric Institute, Erasmus University Rotterdam, P.O.Box 1738, 3000 DR Rotterdam, The Netherlands.

Emails:s.r.ozturk@ese.eur.nl vanderwel@ese.eur.nl djvandijk@ese.eur.nl

We thank participants at PhD seminar in Erasmus University Rotterdam (May, 2014) and Econometrics Seminar in Rutgers University (October, 2014) for their comments. Sait R. Ozturk acknowledges support from Erasmus Trustfonds for his research visit in Rutgers University. Michel van der Wel acknowledges support from CREATES, funded by the Danish National Research Foundation. 
Why do pit-hours outlive the pit?

Sait R. Ozturk Michel van der Wel Dick van Dijk

\begin{abstract}
We study why a majority of trades still happen during the pit hours, i.e. when the trading pit is open, even after the pit ceased to be a liquid and informative venue. We investigate the case of 30-year U.S. Treasury futures using a ten-years-long intraday data set which contains the introduction of the CME Globex platform as an example of sophistication in electronic trading. We use a structural model to estimate the timevariation in potential factors of the clustering of trading activity around the pit hours, namely price informativeness, information asymmetry and price impact of trades. We find evidence for a feedback mechanism between trading activity and these factors. Across the sample period, price informativeness during the afterhours is a consistently significant factor attracting trade activity. Information asymmetry has a negative effect on afterhours activity, particularly during the crisis years. The negative effect of price impact on afterhours activity ceases to be a significant factor from 2007 on, possibly due to improvements in order execution algorithms and electronic trading facilities.
\end{abstract}

Keywords: Afterhours Trading, Market microstructure, Kalman filter.

JEL classifications: C32, G14. 


\section{Introduction}

Over the last two decades, electronic communication networks (ECNs) evolved from auxiliaries of the trading pit to the dominant venues of trading. However one aspect of pit trading, namely high trading activity during the traditional pit trading hours, remains surprisingly resilient. While ECNs have extended potential trading hours to nearly the whole day, the pit hours still enjoy most of the trade volume as well as price the bulk of daily information. We investigate the factors behind the persistence of the high trade activity during the pit hours in a long and recent data set of 30-year U.S. Treasury futures.

Our data set, spanning from 2004 to 2013, allows for examining a number of aspects of the decline in pit trading. The data period contains the recent upsurge in electronic trading systems with the implementation of the Reg NMS framework 1 in the U.S. and the parallel sophistication of ECN platforms, in particular the introduction of the Treasury futures to the CME Globex platform in 2008. This marks the transformation of the trading pit from a significant provider of price discovery to a redundant venue with little trading activity, leading to the CME decision to close the trading pits for U.S. Treasury futures by July 2015. The large jump in trading activity - downwards for the pit and upwards for the ECNs at the start of 2008 presents a valuable 'natural experiment' that allows us to examine the characteristics and determinants of afterhours trading under two different settings.

We contribute to the existing literature both in terms of economic content and econometric methodology. We postulate a feedback mechanism between trading activity on the one hand and price informativeness and trading costs on the other hand. Using a modelling framework capturing the intraday variation in price informativeness, information asymmetry and price impact of trades, we examine the existence and evolution of this feedback mechanism over time. Admati and Pfleiderer (1988) provide a theoretical framework for the

\footnotetext{
${ }^{1}$ The regulatory agency for U.S. exchanges, the Securities and Exchange Commission, implemented Regulation National Market System (Reg NMS) in 2007 to enhance the linkage across exchanges and to improve trade efficiency. This regulation is widely regarded as a cornerstone in the proliferation of electronic trading systems.
} 
clustering of trade activity with price informativeness for low degrees of information asymmetry: liquidity traders can cluster with informed traders as long as their adverse selection costs are outweighed by their benefits from informative prices generated by the competition between informed traders. Barclay and Hendershott (2004) present empirical evidence for a mutually reinforcing relationship between the low afterhours trading activity and the two factors related to trading costs, namely adverse selection and price impact, which we also evaluate in this study.

In terms of econometric methodology, we provide a unified framework to estimate structural parameters as time-varying processes. We assume a latent price process, in which price changes originate either from the surprises in the flow of buyer- or seller-initiated trades, namely the order flow, or from price innovations unrelated to the trading process. The surprises encompass the pricing of private information signals, measuring the information asymmetry (Madhavan, Richardson, and Roomans, 1997). As we control for the price changes generated through the private information signals with the surprise term, the innovation process captures the pricing of public information. The latent price is observed with noise. We distinguish the price impact of trades from the rest of noise sources. We model the innovation and noise variances as well as the information asymmetry and the price impact of trades as time-varying processes. This framework improves upon estimation methods for different aspects of afterhours trading by various reduced-form methods and accounts for the time-variation in the structural parameters.

We test two hypotheses to explain the activity clustering around the pit hours. We firstly examine the effect of price discovery in the trading pit. If pit trades are considerably informative, market participants may prefer to trade during the pit hours at more informative prices. We find that for the early years of our sample the trading pit has a considerable share in price discovery. In 2004 pit trades account for $32.0 \%$ of the variation in permanent price innovations. With the introduction of the Globex Platform in 2008, this figures drops to $11.5 \%$ and pit activity declines so rapidly that proper inference is not possible for later years. 
As this fast decline of the pit does not affect the activity clustering around the pit hours, we reject informativeness of pit trading as a significant factor for the persistence of this clustering.

Secondly, we look into the dynamics of the afterhours to discern the factors preventing the diffusion of trading activity from the pit hours, thereby sustaining the activity clustering. In particular, we test the hypothesis of a feedback mechanism between trading activity, price informativeness and trading costs during the afterhours. This temporal focus is based on the consideration that the diffusion of trading activity towards the afterhours is prevented by the dynamics of afterhours trading. Therefore investigating the afterhours will provide insights on whether and to what degree the aforementioned factors prevent or support the low trading activity during the afterhours and thus the activity clustering around pit hours. We find that percentage changes in price informativeness have about a positive one-to-one relationship with the changes in trading activity. By contrast, the changes in information asymmetry and price impact have a negative relationship with afterhours trading activity. We observe a strengthening in the negative effect of information asymmetry during the crisis years. The reduction in trading activity for each one percent increase in information asymmetry moves from a pre-crisis average of $-2.6 \%$ to an average of $-20.8 \%$ from the second half of 2008 to 2010 and drops to $-1.2 \%$ afterwards. In contrast to the persistent effect of information asymmetry, price impact loses its significant effect from the second half of 2007 on.

Several studies estimate structural models for the afterhours trading processes. Barclay and Hendershott (2004) investigate the activity clustering during the afterhours by decomposing the effective spread into adverse selection and fixed components with the Lin, Sanger, and Booth (1995) model and find the trading costs generated by low trading activity during the afterhours as a major factor for the persistence of pit hours trading. He, Lin, Wang, and $\mathrm{Wu}(2009)$ analyse dynamics of round-the-clock price discovery in the U.S. Treasury futures market with the Madhavan et al. (1997) model and find that the information asymmetry as 
well as price informativeness peaks in the preopen. We also use a version of Madhavan et al. (1997), as it is more amenable to using only trade data.

Our estimation methodology is closely related to a growing literature in state space modelling of market microstructure issues. Frijns and Schotman (2009) and Korenok, Mizrach, and Radchenko (2011) estimate the Hasbrouck (1993) model, which we use to measure price discovery during the pit hours, using Kalman filtering. Korenok et al. (2011) also use the Madhavan et al. (1997) model to incorporate order flow dynamics. We extend upon this richer framework by modelling certain microstructure variables as time-varying processes as in Ozturk, Van der Wel, and Van Dijk (2014). In contrast to these models using intraday data, Hendershott and Menkveld (2014) investigate price pressures with a state space model using daily data, thereby avoiding modelling issues like adverse selection based on short-term information.

The remainder of the paper is organized as follows. Section 2 presents the methods we use and formalizes our hypotheses. Section 3 shows descriptive statistics of our 30-year U.S. Treasury futures data set. Section 4 investigates the determinants of the activity clustering around the pit hours by measuring pit informativeness and the dynamics of the afterhours. Section 5 concludes.

\section{Hypotheses and Methodology}

In this section we firstly present our hypotheses. In the second subsection, we outline the information share methodology that we use. Lastly we present a way to estimate a structural model using state space methods.

\subsection{Hypotheses}

We have two hypotheses regarding the activity clustering around the pit hours. The first hypothesis looks at the pit hours to explain the attraction of trading activity to this time interval and poses the informativeness of pit trading as a cause for the preference of trading 
during the pit hours. The second hypothesis relates to the feedback loop between trading activity and variables related to informational and transaction costs and price informativeness as a source of the clustering.

Hypothesis 1: The trading pit constitutes an important venue for price discovery. Trading activity clusters around the pit hours, because traders benefit from more informed prices emerging from the trading pit.

The relative informativeness of the prices in the trading pit can pose a straightforward reason why the pit hours still attract the bulk of trade volume. A large literature shows that pit traders manage to avoid adverse selection problems through longstanding relationships and reputation and attract mainly uninformed and liquidity-oriented traders (Seppi, 1990; Benveniste, Marcus, and Wilhelm, 1992; Madhavan and Cheng, 1997; Battalio, Ellul, and Jennings, 2007). Contrasting with this largely uninformative order flow into the trading pit, the executions of pit traders seem to propagate price discovery. Sofianos and Werner (2000) note that the floor brokers act like "a smart order book" cutting the order into pieces and executing it strategically over an extended period of time. They condition their trades on the limit order book as well as the hidden liquidity arriving directly to the trading pit and benefit from order imbalances Grossman, 1992; Madhavan and Smidt, 1993; Barclay, Hendershott, and Kotz, 2006). This quality infuses the pit order flow with a high predictive power on the asset's future price (Hasbrouck and Sofianos, 1993; Madhavan and Sofianos, 1998; Kavajecz, 1999; Handa, Schwartz, and Tiwari, 2006).

We analyse the contribution of the trading pit to price discovery using the information share methodology of De Jong and Schotman (2010). This method relies on a structural model related to our model for afterhours trading. The hypothesis implies a considerable amount of price discovery in the trading pit and a positive relationship between the trading activity during the pit hours and the information share of the trading pit.

Hypothesis 2: Trading activity has a positive relationship with price informativeness and negative ones with trading costs related to information asymmetry and price impact. The 
activity clustering persists due to the benefits of trading at already-liquid times of the day, namely more informed prices and less adverse selection and price impact costs.

A mutually-reinforcing relationship between trading activity and other microstructure factors during the afterhours may result in a persistent trading activity difference between parts of the day. The model of Admati and Pfleiderer (1988) implies that the clustering of liquidity and informed traders may be sustained by benefitting both parties: While the informed traders enjoy the reduced impact of their trades, the liquidity traders benefit from the competition between trades with similar information. Information shared by market participants, like public news announcements, would not require trading to be priced, while information shared by fewer traders would be priced through the order flow. Following the theoretical results of Admati and Pfleiderer (1988), we hypothesize that trading activity has a positive relationship with the magnitude of price informativeness and a negative one with the degree of information asymmetry. Also in line with Barclay and Hendershott (2004), we expect a negative relationship between trading activity and price impact of trades. Transaction costs generated by price impact of trades would drive away trading activity and would be further increased due to reduced trading activity.

We test the second hypothesis using time-varying estimates of the relevant variables measuring price informativeness and trading costs. We construct 20 half-yearly series for the afterhours. For each half-year, the regression of trade volume on the measures of the price informativeness, the information asymmetry and the price impact gives the effects of these three variables on trading activity. Our hypotheses imply the regression coefficient to be positive for the price informativeness and negative for the other two variables. A crosssectional regression for each 5-minute period during the afterhours across years constitutes another test for the significance of these relationships across the afterhours. We test this mechanism for the afterhours, because we want to examine the factors sustaining the low afterhours trading activity. 


\subsection{Information Shares}

The first hypothesis requires the measurement of informativeness of trading in the pit compared to the ECN. We accomplish this using the information share methodology of De Jong and Schotman (2010). In this framework, the observed prices of an asset in different venues, in this case in the trading pit and the ECN, are driven by a latent efficient price process. This latent price is modeled as a random walk with stationary innovations $\epsilon_{t}$. The observed asset prices deviate from this latent price with a set of stationary error terms as long-term or unbounded deviations are ruled out by arbitrage. The error terms capture microstructure effects in the observed prices. They comprise two components distinguished by their correlation with the efficient price innovation $\epsilon_{t}$. First, the information-correlated pricing error component captures dynamics such as adverse selection. The second component is uncorrelated with information, but stems from factors such as noise trading or price discreteness.

These relations can be represented as

$$
\begin{aligned}
p_{i, t} & =p_{t}^{*}+\alpha_{i} \epsilon_{t}+e_{i, t}+\psi_{i} e_{i, t-1}, \quad i=E C N, \text { Pit } \\
p_{t}^{*} & =p_{t-1}^{*}+\epsilon_{t}
\end{aligned}
$$

where $p_{i, t}$ is the log observed price, $p_{t}^{*}$ is the latent efficient price, $\epsilon_{t}$ is the innovation in the latent price with mean zero and variance $\sigma_{\epsilon}^{2}$, the coefficients $\alpha_{i}$ capture over/underreaction to the innovations $\epsilon_{t}, e_{i, t}$ are the zero-mean noise disturbances with covariance matrix $\Omega$ and are uncorrelated with the innovations in the latent price as well as other noise $e_{j, t}, i \neq j$, and the coefficients $\psi_{i}$ capture serial correlation in the noise. This would simplify to the Roll (1984) model under no over/underreaction in prices to information $\left(\alpha_{i}=0\right)$, the exclusion of the lagged noise terms $\left(\psi_{i}=0\right)$ and the replacement of the noise terms $e_{t}$ with the effective spread.

De Jong and Schotman (2010) propose a price discovery measure quantifying the ex- 
planatory power of changes in each of the observed security prices for the innovations in the latent price. The total price innovation of each venue in period $t$ is defined as

$$
\nu_{i, t}=p_{i, t}-p_{t-1}^{*}=(1+\alpha i) \epsilon_{t}+e_{i, t}+\psi i, t e_{i, t-1}, \quad i=E C N, \text { Pit. }
$$

To measure informativeness of the venues, we may then consider the regression of the innovation in the latent price on the total innovations in individual prices, that is

$$
\epsilon_{t}=\gamma^{\prime} \nu_{t}+\eta_{t}
$$

where $\eta_{t}$ is the innovation in the latent price unrelated to innovations in market prices.

De Jong and Schotman (2010) decompose the goodness-of-fit of this regression into information shares which show how much of the price innovations is explained by the total innovations in each market. Ozturk, Van der Wel and Van Dijk (2014) show that the information shares are defined as

$$
I S_{i}=\frac{\left(1+\alpha_{i}\right)^{2} /\left(\omega_{i}^{2}\left(1+\psi_{i}^{2}\right)\right)}{1 / \sigma^{2}+\sum_{j=1}^{N}\left(1+\alpha_{j}\right)^{2} /\left(\omega_{j}^{2}\left(1+\psi_{i}^{2}\right)\right)}
$$

and their sum gives the goodness-of-fit of the regression, which does not necessarily equal to one. The model parameters required for the computation of these information shares are estimated using GMM.

\subsection{Structural Model with Intraday Variation}

In order to estimate the variables related to the second hypothesis, we use a richer market microstructure model to evaluate afterhours trading. In the latent price process, we differentiate price innovations incorporated with and without trading. Changes in the beliefs of market participants about asset prices can emerge either from public news or through the signals in the order flow $q_{i, t}$ indicating information asymmetry. We express this difference 
in the structural model by including the surprise in the order flow as a determinant of the changes in the latent price, constraining innovations $\epsilon_{t}$ to changes based on commonly shared information which does not require trading to be priced. Thus the latent price process is defined as

$$
p_{t}^{*}=p_{t-1}^{*}+\theta_{t}\left(q_{t}-E\left[q_{t} \mid q_{t-1}\right]\right)+\epsilon_{t}
$$

where $p_{t}^{*}$ is the latent efficient price, $\left(q_{t}-E\left[q_{t} \mid q_{t-1}\right]\right)$ is the surprise in the order flow, $\theta_{t}$ is the unexpected order flow coefficient and $\epsilon_{t}$ is the public information component of the price innovation with mean zero and time-varying variance $\sigma_{t}^{2}$.

As we estimate this model in the afterhours, the observed price process consists of only the ECN data and the model undergoes three major modifications. The main change is the introduction of a measure of price impact of trades. In particular, we replace $\alpha_{i}$, the under/over-reaction coefficient of observed prices to latent price innovations, with the price impact coefficient $\delta$. This new variable captures the reaction of observed prices to the whole order flow rather than just its informative component. Following prior empirical studies, we model the effect of trade volume as a concave function rather than a linear one (e.g., Kempf and Korn (1999) ). As a minor modification, we allow for more lags of noise to capture the serial correlation in the data created by transitory noise. Thus observed prices follow the process

$$
p_{t}=p_{t}^{*}+\delta_{t} q_{t}+e_{t}+\sum_{j=1}^{J} \psi_{j} e_{t-j}
$$

where $J$ is the number of noise lags, $e_{t}$ are noise terms with mean zero and time-varying variance $\omega_{t}^{2}$ and $\delta_{t}$ is price impact coefficient. Lastly the order flow is modelled as an autoregressive function

$$
q_{t}=\sum_{j=1}^{R} \rho_{j} q_{t-j}+\eta_{t}
$$


where $R$ is set to six using information criteria results.

We estimate equations (5) and (6) by Maximum Likelihood using Kalman filtering. ${ }^{2}$ This estimation method also allows for incorporating more complex dynamics into the model. We model the variance of public price innovation $\sigma_{t}^{2}$, the noise variance $\omega_{t}^{2}$ as well as the coefficients of unexpected order flow $\theta_{t}$ and of the price impact $\delta_{t}$ as time-varying processes. As in Ozturk et al. (2014), we implement time-variation using a combination of flexible Fourier trigonometric functions and a polynomial function. The time-varying parameters have the form

$$
c+\sum_{p=1}^{P} \kappa_{p}(t(\bmod N))^{p}+\sum_{q=1}^{Q}\left(\xi_{q} \cos \left(\frac{2 \pi q t}{N}\right)+\zeta_{q} \sin \left(\frac{2 \pi q t}{N}\right)\right)
$$

where $t$ denotes time with $t=1, \ldots, T, T$ being the number of all observations, $N$ is the number of observations per day, $P$ the order of the polynomial part, and $Q$ the total number of flexible Fourier sets. We use the exponent of this specification for the variances to facilitate an unconstrained maximization procedure given that trigonometric functions can have negative values. The flexible Fourier form can model complex dynamics and smooth transitions. However using solely the flexible Fourier part would impose equality of the variances at the start and end of the day. We avoid this by complementing it with the polynomial component.

\section{Data and Descriptive Statistics}

In this section we firstly introduce some summary statistics of our data set and then provide evidence for the activity clustering around the pit hours.

\footnotetext{
${ }^{2}$ The state space representation of the model is given in Appendix ??.
} 


\subsection{Data}

We employ a data set of intraday transaction prices and volumes of 30-year U.S. Treasury bond futures contracts spanning a 10-years-long period from 2004 to $2013:^{3}$ The trades are time-stamped at the second level. We sign the trades using the tick test $4^{4}$ Trading takes place both in the trading pit and in the ECN. The original trading venue of the contract, the Chicago Board of Trade (CBOT), introduced electronic trading in mid-2003, which moved in January 2008 to the Chicago Mercantile Exchange (CME) Globex platform after the merger of CBOT and CME in July 2007.

The extended trading hours of the ECN allows for the simultaneous incorporation of price movements in the underlying security, the 30-year U.S. Treasury bond, to the futures price. The bond itself trades round-the-clock in Tokyo (19:30h-03:00h EST), London (03:00h-07:30h EST) and New York (07:30h-17:30h EST). The trading of the futures contract happens at 08:20h-15:00h EST for the trading pit. The electronic market for the futures closes during our sample period at 17:00h EST, but its opening time has moved from 20:00h EST in 2004 to 18:00h EST in 2013.

Figure 1 shows the movement of the 30-Year U.S. Treasury futures price during our sample period. The contract price experiences dramatic changes during the financial crisis. The first big jump in December 2008 corresponds to the reduction the federal funds target rate by the Fed. In the first half of 2009, the price returns to its level before the jump in December 2008. In mid-2010 the European debt crisis and stock market volatility lead to a flight to safety causing another appreciation in the Treasury futures price. While this movement starts to reverse in late 2010, S\&P's downgrade of U.S. debt in August 2011 results in even more demand for U.S. debt, triggering new highs for the last years of our

\footnotetext{
${ }^{3}$ The 30-year Treasury bond was discontinued from February 2002 to February 2006 and the futures contract was priced using the substitutes provided by the U.S. Treasury: The Long-Term Average Rate until June 2004 and afterwards an extrapolation factor to compute an estimated 30-year rate using the 20-year Constant Maturity rate.

${ }^{4}$ We did robustness checks for a number of time intervals using the considerably more computationally intensive method of Hasbrouck (2004). This provided very similar results for the 5-minute aggregates we use in the estimation of the state space model.
} 
sample.

[insert Figure 1 here]

The introduction of the Globex Platform in 2008 transforms the relationship between electronic and pit trading fundamentally and irreversibly. Table 1 presents yearly summary statistics for our data set. The pit hours statistics in Panel A show that from the start of the ECN on, the trading pit has a relatively small share in the number of trades with 1,232 pit trades compared to 11,124 ECN trades in 2004. Pit trading practically disappears after the introduction of the Globex in 2008, reducing the annual average of the daily number of pit trades from 310 in 2007 to 69 in 2008. By 2013, merely 6 trades per day occur in the pit. Figure 2 displays the number of trades executed in the trading pit compared to the ECN over time in more detail. In early 2008, a discrete drop in pit trading accompanies a jump in ECN activity. Given the lack of a parallel increase in ECN trade volume, the main driver behind the surge in amount of trades in the ECN seems to be the rise of algorithms to cut larger trades in smaller pieces and disperse the execution of these pieces across the day. As Table 1 shows, the ECN trade volume during the pit hours plummets from the peak of 286,336 in 2007 to 148,358 in 2009 and rises back to 240,779 in 2013.

$$
\text { [insert Table } 1 \text { and Figure } 2 \text { here] }
$$

\subsection{Activity clustering}

In contrast to the severe decline in the number of pit trades, especially after 2007, Figure 3 shows that the pit hours consistently attract a plurality of the ECN trade volume over the years. The share of the pit hours in ECN trade volume declines only from $87.6 \%$ in 2004 to $73.4 \%$ in $20135^{5}$ This modest trend of trading activity diffusion to the afterhours stops during

\footnotetext{
${ }^{5}$ Note that the trade volume has the bigger rises and drops during the minutes before the pit open and after the pit close compared to any other relevant times, e.g., the common market open and close times of U.S. stock exchanges (9:30h-16:00h EST). This is the reason why we relate this activity clustering to the legacy of the work hours of the trading pit.
} 
the early years of the financial crisis, restarting again from 2010 on. This short interlude during the crisis years may be the result of the increasing importance of macroeconomic announcements made during the pit hours and a stronger preference for trading in more liquid times of the day.

[insert Figure 3 here]

This mild diffusion of trading activity to the afterhours happens unevenly across afterhours periods. Panel B of Table 1 reports summary statistics of four afterhours periods: Tokyo hours (ECN Open-03:00h EST), London hours (03:00h-6:20h EST), preopen (6:20h8:20h EST) and postclose (15:00h-17:00h EST). Compared to other parts of the day, the ECN trade volume during the pit hours has the lowest relative increase during our 10-yearslong sample period. While the pit hours volume grows by $26.0 \%$, the trade volumes in the Tokyo hours, the London hours, the preopen and the postclose increase by $199.3 \%, 401.7 \%$, $261.5 \%$ and $131.4 \%$, respectively. However the changes in absolute values amount to less spectacular $21.0 \%$ more increase during the afterhours compared to the pit hours: The total trade volume increase during the afterhours from 2004 to 2013 is 60,204 contracts, compared to a magnitude of 49,760 for the pit hours.

Building on the premise that the introduction of the Globex platform in January 2008 seals the fate of pit trading, as shown in Figure 2, we split the sample period into preGlobex (2004-2007) and Globex (2008-2013). Figure 4 contrasts the intraday distribution of ECN trade volume and trade size for these two periods. Although the clustering of the trade volume during the pit hours is virtually the same in the two periods, the average trade size is more than halved during the Globex period and gets more even across the day. The reduction in average trade size signals the introduction of aforementioned algorithmic trading facilities to execute big orders with a series of small trades. The small increases at both 2:00h EST and 3:00h EST relate to the changing hours of the London market open for a few days in each year due to daylight saving time differences. 
[insert Figure 4 here]

Lastly, we use modified versions of two frequently-used measures of liquidity and price discovery to compare the pre-Globex and Globex periods. The Amihud (2002) illiquidity measure (AIL) and weighted price contributions (WPC) are adapted to measure illiquidity and price discovery in 10-minute intervals across the day. They are defined as

$$
\begin{aligned}
A I L_{t} & =\frac{1}{N} \sum_{n=1}^{N} \frac{\Delta p_{n, t}}{p_{n, t} V o l_{n, t}}, \\
W P C_{t} & =\sum_{n=1}^{N} \frac{\left|\Delta p_{n}\right|}{\sum_{n=1}^{N}\left|\Delta p_{n}\right|} \frac{\Delta p_{n, t}}{\Delta p_{n}},
\end{aligned}
$$

where $\Delta p_{n, t}=p_{n, t}-p_{n, t-1}, p_{n, t}$ is the price at intraday time $t$ of day $n$ with $t=1, \ldots, T$ and $n=1, \ldots, N, \Delta p_{n}=p_{n}-p_{n-1}, p_{n}$ is the price at the pit close (15:00h EST) of day $n$ and $V o l_{n, t}$ is the ECN trade volume for the intraday interval from time $t-1$ to $t$ at day $n$.

Figure 5 compares the intraday distribution of liquidity and price discovery with these preliminary indicators. In line with the mild diffusion of the trade volume to the afterhours in Figure 4, the Amihud illiquidity drops for the afterhours, but remains far larger than the pit hours illiquidity. The average illiquidity of the pit hours measured by the average price change generated by the same amount of dollar-volume increases by $61.5 \%$ from pre-Globex to Globex years, mainly due to a surge at the start of the financial crisis. However the pit hours remain 5.7 times more liquid than the London and preopen hours (a drop from 18.2 times in the pre-Globex years), 1.9 times more liquid than the postclose hours (a decline from 3.7 times) and 27.5 times more liquid than the Tokyo hours (a drop from 96.2 times).

\section{[insert Figure 5 here]}

The WPC statistics in Figure 5 indicate a small trend towards the dispersion of price discovery to the afterhours in line with the changes in trading activity. The total contributions of the pit hours decrease from the $77.0 \%$ share of the pre-Globex years to $67.4 \%$ for the Globex years. The total contributions at the London and preopen hours increase from $12.5 \%$ 
to $18.3 \%$ and that of the Tokyo hours from $5.0 \%$ to $10.0 \%$. Unlike other afterhours periods, the share of postclose hours in price discovery experiences a drop from $5.5 \%$ to $3.5 \%$. We also note a slight shift of informativeness from day open to day close parallel to the shift in trade volumes in Figure 4 .

All in all, we document that a large portion of trades happen during pit hours, while there is only a modest trend towards the dispersion of the trading activity to the afterhours. The introduction of the Globex platform certainly improved the conditions of the afterhours for trading. However this improvement mostly remains an amelioration over the past conditions of the afterhours rather than catching up with the advantages of the pit hours. In particular, relative to the pre-Globex period the same total dollar-volume generates significantly less price change during the afterhours, but this price change remains still at least double of that generated during the pit hours. Afterhours prices become mildly more informative as the share of the daily price change generated by the afterhours increases from a quarter to a third. Only in the average trade sizes we find an equalization across different times of the day, which reduces the ability to trade with relatively bigger sizes in the pit hours without signalling one's trading objectives.

\section{Why does the trading activity cluster around the pit hours?}

In this section we test the two hypotheses outlined in section 2.1. We firstly check the informativeness of the pit trading over time, as trading with more informative prices may be a reason for the ECN participants to choose to trade during the pit hours. Secondly, we investigate how price informativeness and costs related to adverse selection and price impact affect trading activity during the afterhours.

\subsection{Is pit trading informative?}

Table 2 reports the information share results for the pit and the ECN over the years. We estimate the parameters of the structural model represented by equation (1) using GMM 
and compute the information shares of both venues as in equation (4) $!^{6}$ The trading pit accounts for $32.0 \%$ of the price discovery in 2004 compared to the $65.1 \%$ of the ECN. This figure drops to $21.8 \%$ already in 2007, while the share of the ECN increases to $73.9 \%$. In line with the reduction in the number of trades in the pit, in 2008 the information share of the pit further declines to $11.5 \%$, whereas the ECN sustains its dominance with a share of $69.8 \% .7$ From 2009 on, the price staleness in the pit due to the pit hosting only 14 trades per day, as shown in Table 1, impedes inferences on price discovery. The hypothesis of cointegration between the price series of the pit and the ECN is rejected for an increasing majority of days and the structural model is rejected by the Hansen's J-test.

$$
\text { [insert Table } 2 \text { here] }
$$

These results attest to the informativeness of pit trading compared to its share in the number of trades as well as its rapid demise with the sophistication in the electronic trading. From 2004 to 2007, in spite of the shift in the ratio of the number of trades during the pit hours from seven-fold to 22 -fold in favor of the ECN, the share of the pit in price discovery is reduced relatively milder, from one-third to one-fifth. Even when the more dramatic change caused by the introduction of the Globex platform in 2008 increases the ratio of the number of trades to 243-fold in favor the Globex, the pit still retains one-tenth of the information share. However, for the later years even if the few remaining pit trades continue to be very informative in line with the past evidence, their rarity should bring down the contribution of the trading pit to price discovery. Therefore the informativeness of the trading pit should have substantially declined over the second half of the sample, even if not proportional to the drop in the number of pit trades.

\footnotetext{
${ }^{6}$ The validity of this structural model for the data can be tested using Hansen's J-test. Doing so, we do not reject the null hypothesis of model validity for the data from 2004 to 2008 at the $5 \%$ significance level.

${ }^{7}$ In a simulation study, available upon request, we tested the effect of price staleness on the measurement of price discovery. This study implies that the increase of the price staleness in the pit data would decrease estimation accuracy, in particular by underestimating the pit information share. Thus the sizable information share of the trading pit even after the reduction in pit trades starting with 2008 is probably not an overestimate.
} 
The substantial reduction in pit activity and price discovery from 2008 on does not cause a similar shift in the activity clustering around the pit hours. As shown in Figure 3 , the modest trend towards the diffusion of the trading activity to the afterhours actually halts in 2008. The financial crisis may have acted as a strong counterforce by increasing the importance of macroeconomic news announcements during the pit hours. However when this possible effect subsides during the recovery of the later years and the trading pit is reduced to a symbolic venue with less than 10 trades per day during the last four years of our sample, we still do not observe a decline of the same order of magnitude for the activity clustering.

In summary, we reject the Hypothesis 1 stating that market participants' preference for trading during the pit hours due to the informativeness of pit trading can explain the activity clustering. The pit has a considerable share in price discovery compared to its share in trading activity at least in the first half of our sample. However the rapid shrinkage of pit activity after the implementation of the Globex ECN is not accompanied by a shift in the activity clustering.

\subsection{What determines trading activity during the afterhours?}

In this section we use the estimates from the structural model presented in section 2.3 to discern the dynamics of afterhours trading and to evaluate Hypothesis 2. Firstly we present

the intraday estimates. Then we compare the estimates across four afterhours periods. Lastly we test whether the effects of price informativeness, information asymmetry and price impact on trading activity conform with our second hypothesis and can provide an answer to our main research question.

Figure 6 presents the dynamics of trade volume and the estimates of the public information variance from the structural model presented in equations (5) and (6). We estimate the model 20 times for separate six-months sub-periods. Trade volumes follow a similar pattern across years, as in Figure 4 . Trading is very limited until the opening of the London 
market on 3:00h EST (or 2:00h EST depending on the day-light saving time differences) and a dramatic rise from 7:00h EST on. The level of this pattern changes in line with the annual averages of trade volumes presented in Table 1 . The estimates of public innovation variance $\sigma_{t}^{2}$, which we use as a proxy for the price informativeness, follow a similar pattern, but with different levels. While trade volume peaks during the first halves of 2007 and 2013, innovation variance peaks in the second halves of 2008 and 2011. Thus trading activity peaks at the end of stable periods like the last half-year before the Quant Meltdown of August 2007 or the U.S. recovery after the financial crisis. In contrast, the innovation variance climaxes during the heights of crises like the dramatic reduction of the target interest rate by the Fed in December 2008 or the downgrade of U.S. debt by Standard and Poor's in August 2011.

\section{[insert Figure 6 here]}

Figure 7 displays the other three time-varying parameter estimates. The levels of the coefficients of the unexpected order flow $\theta_{t}$ and the price impact $\delta_{t}$ move in line with the innovation variance $\sigma_{t}^{2}$, peaking at the second halves of 2008 and 2011. However, in contrast to the innovation variance $\sigma_{t}^{2}$, the noise variance $\omega_{t}^{2}$ and the coefficients of the unexpected order flow $\theta_{t}$ and price impact $\delta_{t}$ follow a flatter pattern. Only the two coefficients estimated before market open display a clear downwards slope towards the market open. By contrast, the noise variance $\omega_{t}^{2}$ tends to increase towards the pit hours.

\section{[insert Figure 7 here]}

For a preliminary analysis of the afterhours dynamics, we take the averages of the parameter estimates for the four afterhours periods defined in the previous section: Tokyo hours (ECN Open-03:00h EST), London hours (03:00h-6:20h EST), preopen (6:20h-8:20h EST) and postclose (15:00h-17:00h EST). The ratios of noise variances to innovation variances, exhibited in Figure 8, indicate that prices during each of these afterhours periods become more informative around the implementation of Reg NMS and the introduction of 
the Globex platform. In all six-month subperiods the noisiness of prices decreases monotonically from the ECN open to the pit open due to the rise of innovation variances. During the Tokyo hours the noise variance even exceeds innovation variance for five out of eight pre-Globex half-years. We find the preopen period to be almost always more informative than the postclose period as in Barclay and Hendershott (2003) and He et al. (2009).

[insert Figure 8 here]

Figure 9 presents the afterhours averages for the unexpected order flow coefficient, which is a measure of information asymmetry. By contrast to the noise-to-innovation ratios, the financial crisis has a far bigger effect compared to the concurrent advances in electronic trading. Although information asymmetry reaches its lowest levels at the end of our sample period, it peaks instead of diminishing in 2008 and 2009. The intraday picture exhibits a recurring pattern of monotonic decline in information asymmetry from ECN open to ECN close for the afterhours. The first half of 2007 and the second half of 2011 constitute the sole exceptions with small increases in the preopen compared to the London hours. Most models on market microstructure indicate such a decline in information asymmetry over the trading period (Kyle, 1985; Glosten and Milgrom, 1985; Foster and Viswanathan, 1990; Easley and O’Hara, 1992).

[insert Figure 9 here]

The price impact of trades constitutes a major obstacle for the proliferation of trading. Therefore the sustainability of activity clustering during the pit hours relies on the resilience of the price impact during the afterhours. The mean price impact coefficients during afterhours periods, shown in Figure 10, peak in 2008 and 2009 and return to their prior level in 2010. We see a downward shift in price impact only from 2012 on. In the first half of 2012, the price impact coefficient drops again to its pre-Globex low in 2006-2007 and reduces even further from the second half of 2012 on. The gap between night hours and preopen values 
also decreases in the last years. The overall decrease in price impact and the decrease of the differences across afterhours periods constitutes some evidence for the decline of the price impact barrier against trading during the afterhours.

[insert Figure 10 here]

To test the second hypothesis, we take first differences of the natural logarithms of our variables and regress the afterhours trade volume on the proxies of price informativeness, information asymmetry and price impact. As the regressors are estimates themselves, we use the Murphy and Topel (1985) method to calculate correct standard errors. Table 3 reports for each half-year the results of separate regressions for each variable and a regression using all three variables. Price informativeness emerges as the most significant factor explaining intraday changes in trading activity. It has a strong positive relationship with trading activity as postulated and its effect is significant at 5\% level in 13 out of 20 regressions. The coefficient displays little fluctuation across years and indicates that a percentage change in price informativeness relates to a percentage change of the same magnitude for trading activity.

[insert Table 3 here]

The results for information asymmetry and price impact express a weaker relationship with trading activity. Out of the 20 regressions, the effect of information asymmetry is insignificant at 5\% level for four separate regressions and 11 combined ones. Price impact has an insignificant effect for 11 regressions of both types. In the significant cases the signs of the coefficients are almost always in line with the negative effect posited by the second hypothesis. The few exceptions are either very small in terms of magnitude, as is the case for two positive coefficients of information asymmetry in separate regressions, or emerge due to the interaction between price impact and information asymmetry in combined regressions. Including the coefficients of the unexpected order flow (information asymmetry) 
and the total order flow (price impact) in one regression may not be very sensible, because they share the effect of the adverse selection in prices: Information asymmetry measures the informative component of adverse selection and price impact includes the under- and overreaction to this informative component. One may very well capture the effect of the other, if the uninformative component of the price impact is relatively small, making the coefficient estimates difficult to interpret.

The effects of information asymmetry and price impact display a strong time-dependence. The negative relationship of information asymmetry with trading activity peaks during the crisis years, from the second half of 2008 on. In the first half of 2009 a one percent change in information asymmetry causes a trading activity drop with a magnitude more than $30 \%$. This increased negative effect subsides starting with 2011. In the case of the price impact the significance rather than the magnitude of the relationship shifts over time. Starting with the second half of 2007 the significant influence of price impact on trading activity disappears with a few exceptions. This can again be related to the rise of algorithmic trade execution systems allowing the execution of large orders in small batches, which reduces the price impact costs for electronic trading. Thus price impact of trades ceases to be a significant reason for not trading in relatively illiquid periods.

We can test these relationships also cross-sectionally for each 5-minute interval of the afterhours. Figure 11 reports the coefficient estimates generated by regressing the changes in trade volume on the contemporaneous changes in the estimates of public innovation variance, unexpected order flow coefficient and price impact coefficient. Although we have a small number of observations per regression (19 at best), for 51, 50 and 61 out of the 184 5minute intervals we find the regression coefficients to be significant at $5 \%$ level for the price informativeness, information asymmetry and price impact regressions, respectively.

$$
\text { [insert Figure } 11 \text { here] }
$$

The signs of the statistically significant regression coefficients are in line with the time series regressions and the second hypothesis. In all cases we observe a less than one-to-one 
effect of percentage changes in the three variables on trading activity. Although the postclose period has the highest share of significant cases, the effects of information asymmetry and price impact are negligibly small for the year-to-year changes, mainly due to the large increases they experience during the crisis years.

In summary, we find nuanced but positive evidence for the second hypothesis. Price informativeness during the afterhours has a significant positive relationship with trading activity. The negative relation between information asymmetry and trading activity has risen particularly during the financial crisis. Price impact requires a more refined interpretation, because its negative relation with trading activity loses its significance from the second half of 2007 on.

\section{Conclusion}

In this paper, we investigate the factors behind the concentration of trading around the pit hours. For the case of the U.S. Treasury futures, about three quarters of trades happen during this 400 minutes of a trading day. However, we document a mild secular trend towards the erosion of this clustering. We find the largest trade volume increases during the trade hours of the London market for U.S. Treasury futures and the largest drops in Amihud (2002) illiquidity during the Tokyo market hours. The recent financial crisis stops this trend at least for a while, probably because of the increasing importance of macroeconomic announcements made during the pit hours and a stronger preference for trading in more liquid times of the day.

We find the informativeness of pit trades to be an unsatisfactory explanation for the activity clustering. The trading pit indeed has a sizable share in price discovery before the introduction of the Globex Platform in 2008. However the substantial reduction of pit trading after 2008 does not cause a significant change in the mild erosion trend of the trading activity share of the pit hours. The last few years make this conclusion clearer as the dynamics generated by the financial crisis subside. 
We use a structural model estimated with state space methods to analyze afterhours trading. Public information variance displays a strong time-varying pattern similar to trade volumes, increasing near open and close times of different markets ad towards the pit hours. We observe flatter patterns, but considerable differences across afterhours periods for the coefficients of the order flow and the unexpected order flow, measuring price impact and information asymmetry respectively. The preopen stands out as the most informative afterhours period, while the postclose has the least information asymmetry. Discounting for the effects of the financial crisis, we observe a progressive decrease during the afterhours for information asymmetry, price impact of trades and the amount of noise in prices, attributable to the improvements in electronic trading.

Our findings confirm price informativeness and costs related to information asymmetry and price impact as significant explanatory factors for activity clustering. Price informativeness during the afterhours has a stable and strong positive relationship with the distribution of trading activity. Information asymmetry generates adverse selection costs pushing liquidity traders away and its effect is particularly strong in the crisis period. Price impact costs, on the other hand, have a negative effect on trading activity until the second half of 2007, but cease to be a significant factor afterwards. We attribute this change to the improvements in algorithmic execution systems in the same period which have a documented diminishing effect on trade sizes with the introduction of the Globex Platform. 


\section{References}

Admati, A. R. and P. Pfleiderer (1988). A theory of intraday patterns: Volume and price variability. Review of Financial Studies 1(1), 3-40.

Amihud, Y. (2002). Illiquidity and stock returns: cross-section and time-series effects. Journal of Financial Markets (5), 3156.

Barclay, M. J. and T. Hendershott (2003). Price discovery and trading after hours. Review of Financial Studies 16(4), 1041-1073.

Barclay, M. J. and T. Hendershott (2004). Liquidity externalities and adverse selection: Evidence from trading after hours. Journal of Finance 59(2), 681-710.

Barclay, M. J., T. Hendershott, and K. Kotz (2006). Automation versus intermediation: Evidence from treasuries going off the run. Journal of Finance 61 (5), 2395-2414.

Battalio, R., A. Ellul, and R. Jennings (2007). Reputation effects in trading on the New York Stock Exchange. Journal of Finance 62(3), 1243-1271.

Benveniste, L. M., A. J. Marcus, and W. J. Wilhelm (1992). What's special about the specialist? Journal of Financial Economics 32(1), 61-86.

De Jong, F. and P. Schotman (2010). Price discovery in fragmented markets. Journal of Financial Econometrics 8(1), 1-28.

Easley, D. and M. O'Hara (1992). Time and the process of security price adjustment. Journal of Finance $47(2), 577-605$.

Foster, F. D. and S. Viswanathan (1990). A theory of the interday variations in volume, variance, and trading costs in securities markets. Review of Financial Studies 3(4), 593624.

Frijns, B. and P. Schotman (2009). Price discovery in tick time. Journal of Empirical Finance 16, 759-776.

Glosten, L. R. and P. R. Milgrom (1985). Bid, ask and transaction prices in a specialist market with heterogeneously informed traders. Journal of Financial Economics 14(1), $71-100$.

Grossman, S. J. (1992). The informational role of upstairs and downstairs trading. Journal of Business $65(4), 509$.

Handa, P., R. Schwartz, and A. Tiwari (2006). The economic value of a trading floor: Evidence from the American Stock Exchange. In R. A. Schwartz, J. A. Byrne, and A. Colaninno (Eds.), Electronic vs. Floor Based Trading, pp. 121-151. US: Springer.

Hasbrouck, J. (1993). Assessing the quality of a security market: a new approach to transaction-cost measurement. Review of Financial Studies 6, 191212.

Hasbrouck, J. (2004). Liquidity in the futures pits: Inferring market dynamics from incomplete data. Journal of Financial and Quantitative Analysis 39(2), 305-326. 
Hasbrouck, J. and G. Sofianos (1993). The trades of market makers: An empirical analysis of NYSE specialists. Journal of Finance 48(5), 1565-1593.

He, Y., H. Lin, J. Wang, and C. Wu (2009). Price discovery in the round-the-clock U.S. treasury market. Journal of Financial Intermediation 18(3), 464-490.

Hendershott, T. and A. J. Menkveld (2014). Price pressures. Journal of Financial Economics 114, 405-423.

Kavajecz, K. A. (1999). A specialist's quoted depth and the limit order book. Journal of Finance $54(2), 747-771$.

Kempf, A. and O. Korn (1999). Market depth and order size. Journal of Financial Markets 2(1), 29-48.

Korenok, O., B. Mizrach, and S. Radchenko (2011). A structural approach to information shares.

Kyle, A. S. (1985). Continuous auctions and insider trading. Econometrica 53(6), 1315-1335.

Lin, J.-C., G. Sanger, and G. G. Booth (1995). Trade size and components of the bidask spread,. Review of Financial Studies 8, 11531183.

Madhavan, A. and M. Cheng (1997). In search of liquidity: Block trades in the upstairs and downstairs markets. Review of Financial Studies 10(1), 175-203.

Madhavan, A., M. Richardson, and M. Roomans (1997). Why do security prices change? a transaction-level analysis of NYSE stocks. Review of Financial Studies 10, 10351064.

Madhavan, A. and S. Smidt (1993). An analysis of changes in specialist inventories and quotations. Journal of Finance 48(5), 1595-1628.

Madhavan, A. and G. Sofianos (1998). An empirical analysis of NYSE specialist trading. Journal of Financial Economics 48, 189-210.

Murphy, K. M. and R. H. Topel (1985). Estimation and inference in two-step econometric models. Journal of Business and Economic Statistics 3(4), 370-379.

Ozturk, S. R., M. Van der Wel, and D. J. Van Dijk (2014). Intraday price discovery in fragmented markets.

Roll, R. (1984). A simple implicit measure of the effective bidask spread in an efficient market. Journal of Finance 39(4), 1127-1139.

Seppi, D. J. (1990). Equilibrium block trading and asymmetric information. Journal of Finance 45(1), 73-94.

Sofianos, G. and I. M. Werner (2000). The trades of NYSE floor brokers. Journal of Financial Markets 3(2), 139-176. 


\section{Appendix}

\section{The state space representation of the structural model}

In the state space form, the structural model of section 2.3 model given in equations (5) and (6) can be represented by these two equations:

$$
\begin{aligned}
& p_{t}=\delta_{t} q_{t}+\left[\begin{array}{llll}
1 & 1 & 1 & \psi_{1, j}
\end{array}\right]\left[\begin{array}{c}
p_{t-1}^{*} \\
\epsilon_{t-1} \\
e_{t-1, j}
\end{array}\right]+G \varepsilon_{t}, \text { where } G=\left[\begin{array}{ll}
1 & 1
\end{array}\right] \text { and } \varepsilon_{t}=\left[\begin{array}{c}
\epsilon_{t} \\
e_{t}
\end{array}\right] \\
& {\left[\begin{array}{c}
p_{t}^{*} \\
\epsilon_{t} \\
e_{t, j}
\end{array}\right]=\left[\begin{array}{c}
\theta_{t}\left(q_{t}-E\left[q_{t} \mid q_{t-1}\right]\right) \\
0_{(1+J) \times 1}
\end{array}\right]+\left[\begin{array}{cccc}
1 & 0 & 0_{1 \times J} & 0 \\
0 & 0 & 0_{1 \times J} & 0 \\
0 & 0 & 0_{1 \times J} & 0 \\
0 & 0 & 0_{J \times 1} & 0_{J \times 1}
\end{array}\right]\left[\begin{array}{c}
p_{t-1}^{*} \\
\epsilon_{t-1} \\
e_{t-1, j}
\end{array}\right]+H \varepsilon_{t},} \\
& \text { where } H=\left[\begin{array}{cc}
1 & 0 \\
1 & 0 \\
0 & 1 \\
0_{J \times 1} & 0_{J \times 1}
\end{array}\right]
\end{aligned}
$$

with $\psi_{n, m}$ a stacked row vector of $\psi_{j}$ coefficients from the $n^{\text {th }}$ to the $m^{t h}, e_{t-n, m}$ a stacked column vector of disturbances $e_{j}$ from time $t-n$ to time $t-n-m, 0_{n \times m}$ an $n \times m$ matrix of zeros, $I_{n}$ is an $n \times n$ identity matrix. The variance parameters are uniquely identified using the covariance matrix of the stacked disturbances $\left[\begin{array}{c}H \\ G\end{array}\right] \varepsilon_{t}$, which comprises the innovation 
and noise variances:

$$
\left.E\left[\begin{array}{c}
H \\
G
\end{array}\right] \varepsilon_{t} \varepsilon_{t}^{\prime}\left[\begin{array}{c}
H \\
G
\end{array}\right]^{\prime}\right]=\left[\begin{array}{ccccc}
\sigma_{t}^{2} & \sigma_{t}^{2} & 0 & 0_{1 \times J} & \sigma_{t}^{2} \\
\sigma_{t}^{2} & \sigma_{t}^{2} & 0 & 0_{1 \times J} & \sigma_{t}^{2} \\
0 & 0 & \omega_{t}^{2} & 0_{1 \times J} & \omega_{t}^{2} \\
0_{J \times 1} & 0_{J \times 1} & 0_{J \times 1} & 0_{J \times J} & 0_{J \times 1} \\
\sigma_{t}^{2} & \sigma_{t}^{2} & \omega_{t}^{2} & 0_{1 \times J} & \sigma_{t}^{2}+\omega_{t}^{2}
\end{array}\right] .
$$




\section{Table 1. Summary Statistics}

We report for various intraday intervals the mean number of trades and trade volumes as well as the means and the standard deviations of 5-minute returns in basis points.

Panel A: Pit and ECN Statistics for the Pit Hours (8:20h-15:00h EST)

\begin{tabular}{|c|c|c|c|c|c|c|c|c|}
\hline & \multicolumn{4}{|c|}{ Pit } & \multicolumn{4}{|c|}{ ECN } \\
\hline & Tr. Vol ${ }^{a}$ & Num. of Tr. & Mean & Std. Dev. & Tr. Vol. & Num. of Tr. & Mean & Std. Dev. \\
\hline 2004 & & 1232 & -0.129 & 11.622 & 191019 & 11124 & 0.015 & 6.173 \\
\hline 2005 & & 671 & 0.103 & 7.530 & 235934 & 10655 & 0.012 & 4.792 \\
\hline 2006 & & 559 & -0.100 & 6.063 & 256834 & 8167 & -0.002 & 4.270 \\
\hline 2007 & & 310 & -0.318 & 6.815 & 286336 & 8471 & 0.014 & 4.799 \\
\hline 2008 & & 69 & 0.381 & 14.554 & 220149 & 20509 & 0.045 & 7.704 \\
\hline 2009 & & 14 & -0.617 & 15.698 & 148358 & 21836 & -0.022 & 8.351 \\
\hline 2010 & & 9 & 0.189 & 12.742 & 208236 & 27794 & 0.024 & 6.097 \\
\hline 2011 & & 7 & -0.281 & 14.626 & 234472 & 45446 & 0.117 & 6.664 \\
\hline 2012 & & 5 & -0.134 & 12.265 & 225187 & 68412 & 0.017 & 4.976 \\
\hline 2013 & & 6 & -0.392 & 12.403 & 240779 & 63771 & -0.036 & 5.048 \\
\hline
\end{tabular}

Panel B: ECN Statistics for the Afterhours

\begin{tabular}{|c|c|c|c|c|c|c|c|c|}
\hline & \multicolumn{4}{|c|}{ Tokyo hours (ECN Open-03:00h EST) } & \multicolumn{4}{|c|}{$\begin{array}{l}\text { London hours (03:00h-6:20h EST) } \\
\text { (0) }\end{array}$} \\
\hline & Tr. Vol. & Num. of Tr. & Mean & Std. Dev. & Tr. Vol. & Num. of Tr. & Mean & Std. Dev. \\
\hline 2004 & 4245 & 389 & -0.038 & 2.537 & 4439 & 342 & 0.027 & 2.493 \\
\hline 2005 & 6249 & 407 & -0.011 & 1.874 & 7443 & 437 & 0.009 & 2.471 \\
\hline 2006 & 8397 & 401 & 0.012 & 1.734 & 10754 & 432 & -0.036 & 2.287 \\
\hline 2007 & 10076 & 512 & 0.008 & 2.011 & 12836 & 532 & 0.003 & 2.649 \\
\hline 2008 & 7089 & 1126 & 0.018 & 2.845 & 9862 & 1188 & 0.076 & 3.725 \\
\hline 2009 & 4454 & 1093 & -0.006 & 2.585 & 6354 & 1254 & 0.000 & 3.771 \\
\hline 2010 & 7912 & 1772 & 0.017 & 2.507 & 11852 & 2138 & 0.034 & 3.511 \\
\hline 2011 & 9383 & 2491 & 0.005 & 2.813 & 16177 & 4161 & -0.029 & 4.114 \\
\hline 2012 & 10268 & 3459 & 0.000 & 2.181 & 21501 & 7794 & 0.037 & 3.453 \\
\hline \multirow[t]{3}{*}{2013} & 12707 & 3968 & 0.022 & 2.273 & 22273 & 6868 & -0.022 & 3.150 \\
\hline & \multicolumn{4}{|c|}{ Preopen (6:20h-8:20h EST) } & \multicolumn{4}{|c|}{ Postclose (15:00h-17:00h EST) } \\
\hline & Tr. Vol. & Num. of Tr. & Mean & Std. Dev. & Tr. Vol. & Num. of Tr. & Mean & Std. Dev. \\
\hline$\overline{2004}$ & 7424 & 524 & 0.004 & 3.025 & 11028 & 618 & 0.102 & 2.876 \\
\hline 2005 & 12528 & 663 & -0.030 & 3.002 & 14706 & 623 & 0.069 & 2.476 \\
\hline 2006 & 15469 & 576 & -0.013 & 2.676 & 15451 & 471 & 0.005 & 2.180 \\
\hline 2007 & 18458 & 693 & 0.068 & 3.355 & 24186 & 737 & -0.046 & 3.133 \\
\hline 2008 & 15337 & 1800 & 0.003 & 5.212 & 24418 & 2291 & 0.099 & 5.427 \\
\hline 2009 & 9660 & 1723 & -0.083 & 5.044 & 16369 & 2220 & -0.032 & 4.930 \\
\hline 2010 & 15379 & 2451 & -0.079 & 4.336 & 22376 & 2579 & 0.016 & 3.406 \\
\hline 2011 & 19388 & 4388 & 0.025 & 4.882 & 24141 & 4321 & 0.015 & 4.564 \\
\hline 2012 & 24063 & 7733 & -0.032 & 3.887 & 24796 & 6437 & 0.012 & 2.935 \\
\hline 2013 & 26840 & 7026 & -0.074 & 3.672 & 25521 & 6222 & -0.010 & 3.075 \\
\hline
\end{tabular}

${ }^{a}$ We do not have trade size data for pit trades and therefore we are not able to compute the trade volume statistics for the trading pit. 
Table 2. Yearly Information Shares for the Pit and the ECN

We report the yearly information shares estimated using data sampled at 5 minute frequency. The information share estimates are in percentages.

\begin{tabular}{lcc}
\hline & & Information Shares \\
\hline & ECN & Pit \\
\hline 2004 & 65.1 & 32.0 \\
2005 & 71.2 & 25.0 \\
2006 & 65.5 & 28.1 \\
2007 & 73.9 & 21.8 \\
2008 & 69.8 & 11.5 \\
\hline
\end{tabular}




\section{Table 3. Regressions to Test for activity clustering}

We report the coefficient estimates for the regressions of trade volume on each of the variable estimates separately.

Both the independent and dependent variables are in log differences. The Time column gives the half-year period the trade volume data and the time-varying estimates are based on. The IV, UOF and PI columns give coefficient estimates of public innovation variance, unexpected order flow coefficient and price impact coefficients. These are followed by the mean adjusted $R^{2}$ of the separate regressions and the adjusted $R^{2}$ of the combined regression. The superscript ${ }^{* * *}$ marks significance at level $1 \%,{ }^{* *}$ at level $5 \%$, and ${ }^{*}$ at level $10 \%$. As the regressors are estimates themselves, we use the Murphy and Topel (1985. method to calculate correct standard errors.

\begin{tabular}{|c|c|c|c|c|c|c|c|c|c|}
\hline \multirow[b]{2}{*}{ Time } & \multicolumn{4}{|c|}{ Separate Regressions } & \multicolumn{4}{|c|}{ Combined Regression } & \multirow[b]{2}{*}{$\mathrm{N}$} \\
\hline & IV & UOF & PI & adj. $R^{2}$ & IV & UOF & PI & adj. $R^{2}$ & \\
\hline $2004 \mathrm{a}$ & $1.4^{* * *}$ & $-0.6^{* * *}$ & $-1.3^{* * *}$ & 4.0 & $1.1^{* * *}$ & -0.2 & $-0.6^{*}$ & 5.9 & 164 \\
\hline $2004 b$ & 0.3 & $-7.8^{* *}$ & $-4.2^{* * *}$ & 1.1 & -0.1 & 2.2 & $-4.8^{* * *}$ & 2.7 & 164 \\
\hline $2005 \mathrm{a}$ & $1.2^{* * *}$ & $-3.9^{* *}$ & $-3.6^{* * *}$ & 4.0 & $0.8^{* *}$ & $5.3^{* *}$ & $-5.2^{* * *}$ & 5.9 & 164 \\
\hline $2005 b$ & $0.8^{* *}$ & $-0.6^{* * *}$ & $-2.0^{* *}$ & 2.6 & 0.3 & $-0.6^{* * *}$ & $-2.0^{* * *}$ & 5.1 & 164 \\
\hline $2006 a$ & $0.8^{* * *}$ & $-0.4^{* *}$ & $-6.0^{* *}$ & 2.5 & $0.8^{* * *}$ & 0.0 & $-4.9^{* *}$ & 5.6 & 176 \\
\hline $2006 b$ & $0.6^{* *}$ & 0.0 & $-2.2^{* *}$ & 0.5 & $0.5^{* *}$ & 0.0 & $-1.8^{* *}$ & 1.0 & 176 \\
\hline $2007 a$ & $0.4^{* *}$ & $-4.4^{* *}$ & $-1.3^{* *}$ & 0.5 & 0.2 & $-4.8^{* * *}$ & $-1.4^{* * *}$ & 1.0 & 176 \\
\hline $2007 \mathrm{~b}$ & $0.4^{* * *}$ & -0.1 & -0.2 & 1.1 & $0.3^{* *}$ & 0.8 & -1.0 & 3.4 & 176 \\
\hline $2008 \mathrm{a}$ & $1.6^{* * *}$ & $-0.3^{* *}$ & -0.9 & 2.2 & $1.7^{* * *}$ & $-0.2^{* *}$ & 0.4 & 5.2 & 182 \\
\hline $2008 b$ & $0.6^{* *}$ & $-25.3^{* * *}$ & -2.8 & 2.2 & 0.4 & $-19.5^{* *}$ & -0.2 & 3.2 & 182 \\
\hline $2009 a$ & $0.6^{* * *}$ & $-31.4^{* * *}$ & -1.3 & 3.4 & $0.5^{* * *}$ & $-30.0^{* * *}$ & $1.5^{*}$ & 8.4 & 182 \\
\hline $2009 \mathrm{~b}$ & $1.2^{* * *}$ & $-20.8^{* * *}$ & 0.2 & 3.9 & $0.9^{* * *}$ & $-21.2^{* * *}$ & $-2.9^{* * *}$ & 10.3 & 182 \\
\hline $2010 \mathrm{a}$ & $1.3^{* * *}$ & $-12.6^{* * *}$ & $-0.4^{*}$ & 4.8 & $1.2^{* * *}$ & -4.0 & 0.0 & 11.5 & 182 \\
\hline $2010 \mathrm{~b}$ & $1.0^{* * *}$ & $-13.7^{* * *}$ & -1.0 & 5.0 & $1.0^{* * *}$ & 2.5 & -1.4 & 11.6 & 182 \\
\hline 2011a & $0.7^{* * *}$ & 0.4 & 0.3 & 2.1 & $1.0^{* * *}$ & 1.1 & -0.2 & 9.1 & 182 \\
\hline $2011 b$ & 0.1 & $0.0^{* *}$ & 0.1 & -0.1 & 0.0 & $-0.2^{* *}$ & $0.9^{*}$ & 0.3 & 182 \\
\hline $2012 \mathrm{a}$ & $1.4^{* * *}$ & $-0.7^{* *}$ & 0.0 & 5.6 & $1.4^{* * *}$ & -0.1 & 0.4 & 14.1 & 188 \\
\hline $2012 b$ & $1.1^{* * *}$ & $-4.2^{* *}$ & -0.3 & 4.2 & $1.0^{* * *}$ & $-5.0^{* * *}$ & $1.6^{* *}$ & 12.8 & 188 \\
\hline $2013 \mathrm{a}$ & $1.6^{* * *}$ & $0.0^{* *}$ & $0.2^{* *}$ & 5.6 & $1.5^{* * *}$ & 0.0 & 0.0 & 11.9 & 188 \\
\hline $2013 b$ & $1.0^{* * *}$ & 0.1 & -0.9 & 3.8 & $1.0^{* * *}$ & -0.2 & $-0.7^{* *}$ & 11.5 & 188 \\
\hline
\end{tabular}


Fig. 1. The Movements of the 30-Year U.S. Treasury Futures Price

The figure shows the value of the 30-Year U.S. Treasury Futures over the 4108 trading days from 2004 to 2013. The left axis is the price in USD and the bottom axis gives the days. The data is sampled at 5 -minute frequency.

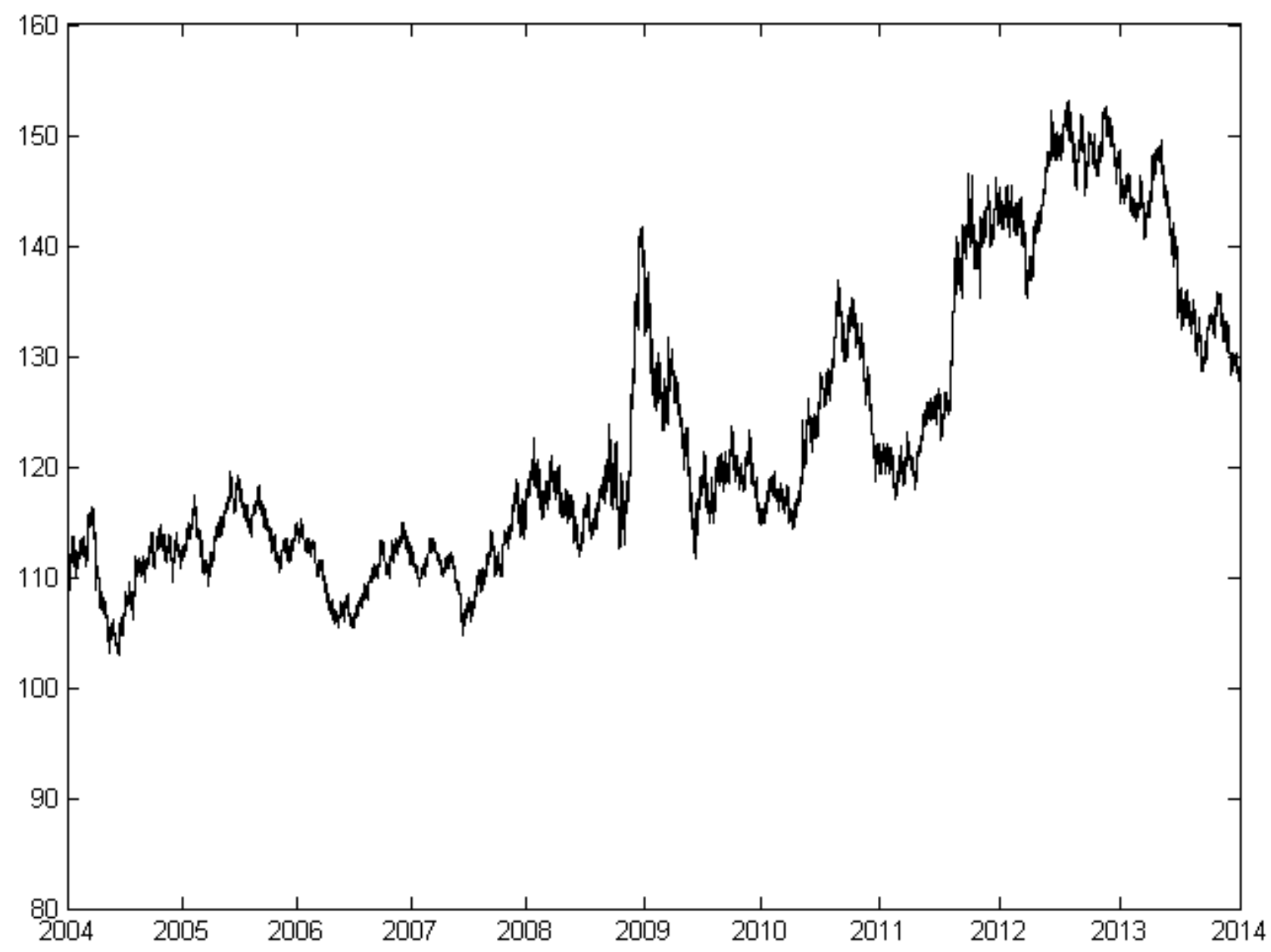


Fig. 2. Number of Trades in the Pit and Electronic Markets

The figure shows the 22-day moving average of the daily number of trades of the 30-Year U.S. Treasury Futures in the pit and the electronic markets from 2004 to 2013. The left and right axes give the number of trades for the trading pit and the ECN, respectively, and the bottom axis gives the days.

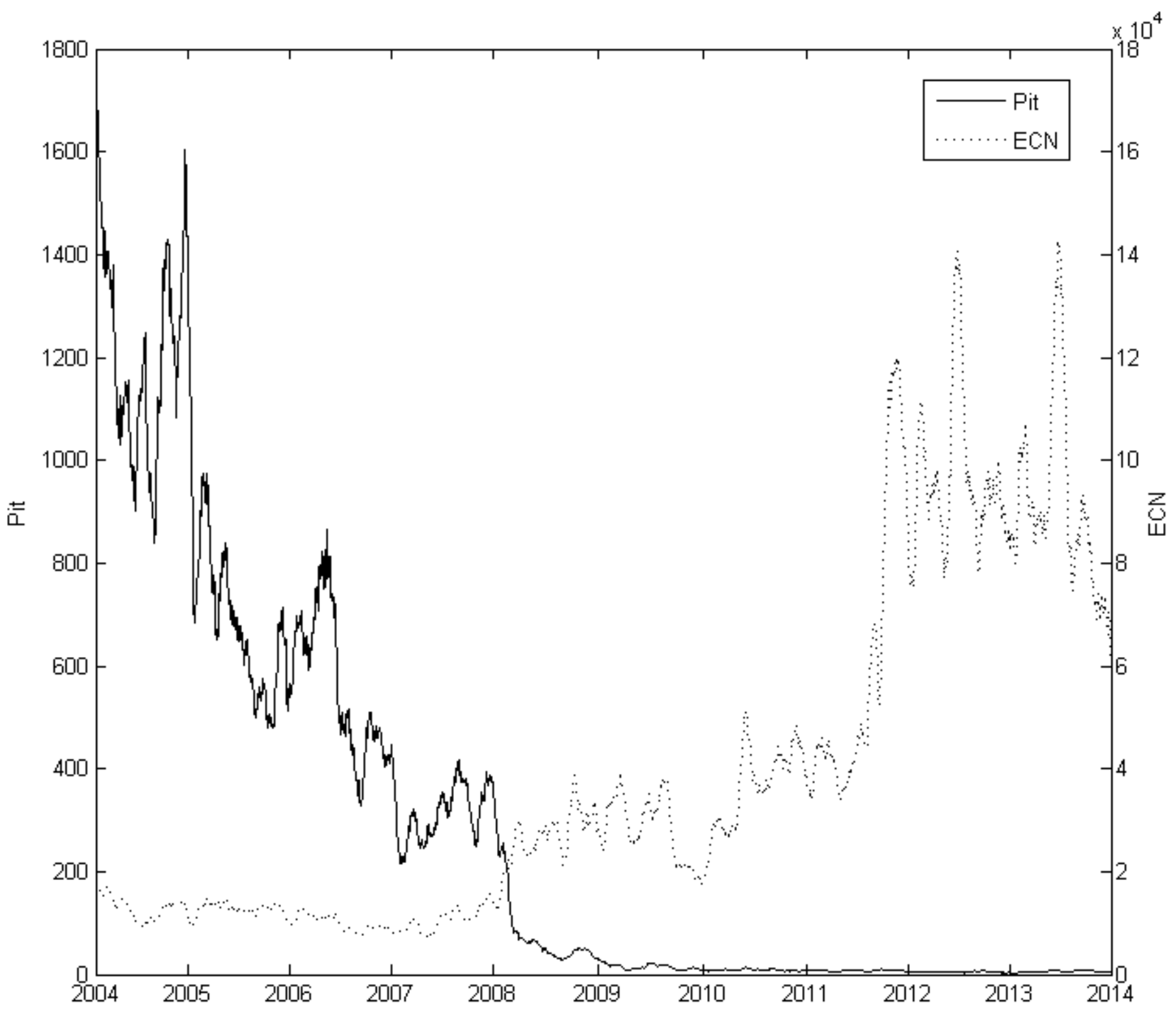


Fig. 3. The Distribution of ECN Trade Volume across Intraday Intervals

The figure shows the intraday distribution of the ECN trade volume for the 30-Year U.S. Treasury Futures from 2004 to 2013. The ratios of intraday periods are computed using 22-day moving averages of the trade volume figures.

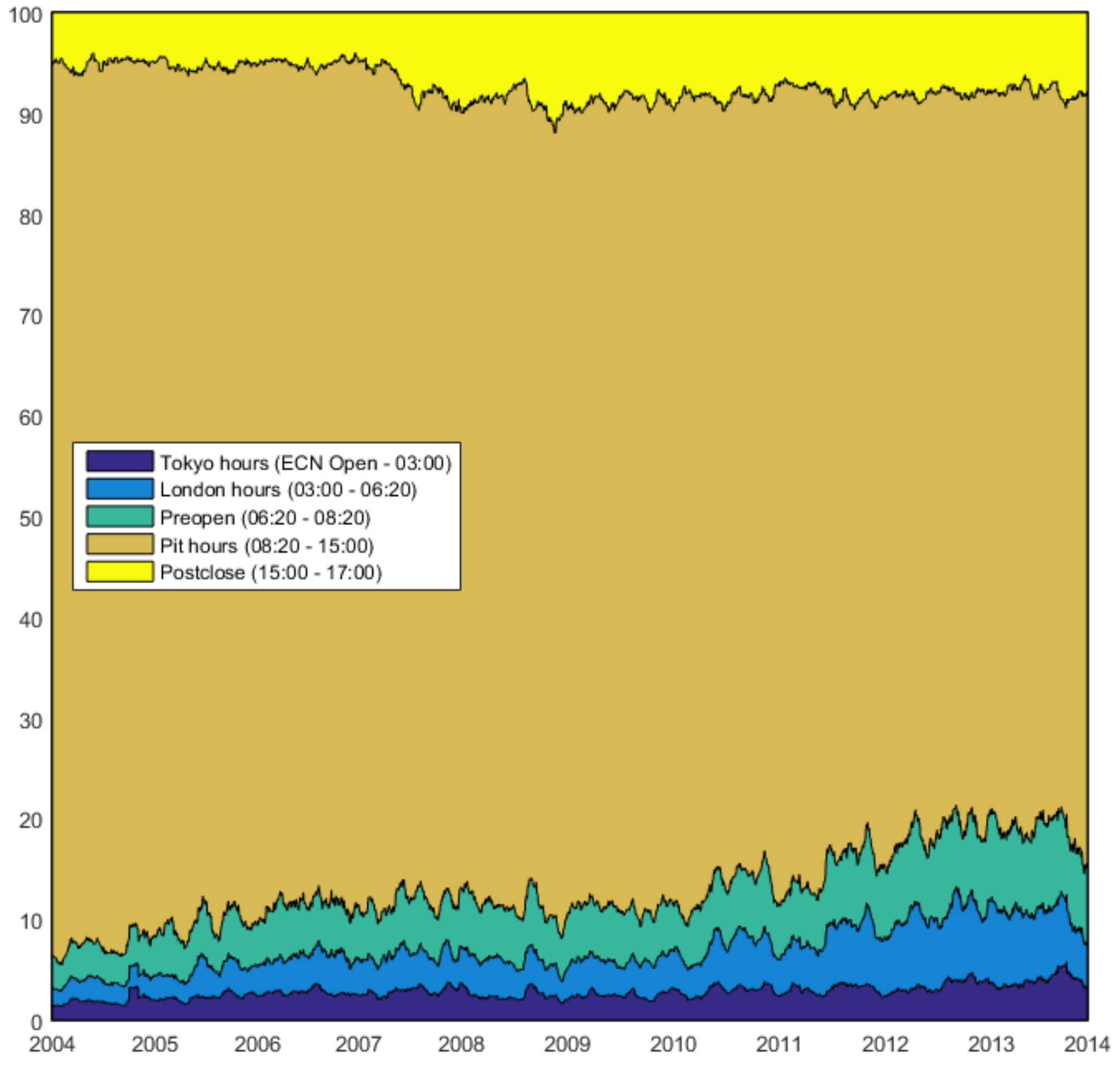


Fig. 4. Intraday Trade Volume and Trade Size of the ECN

The figure shows the mean trade volumes and trade sizes for 10-minute-long intervals across the trading day for two time intervals: from 2004 to 2007 and from 2008 to 2013.

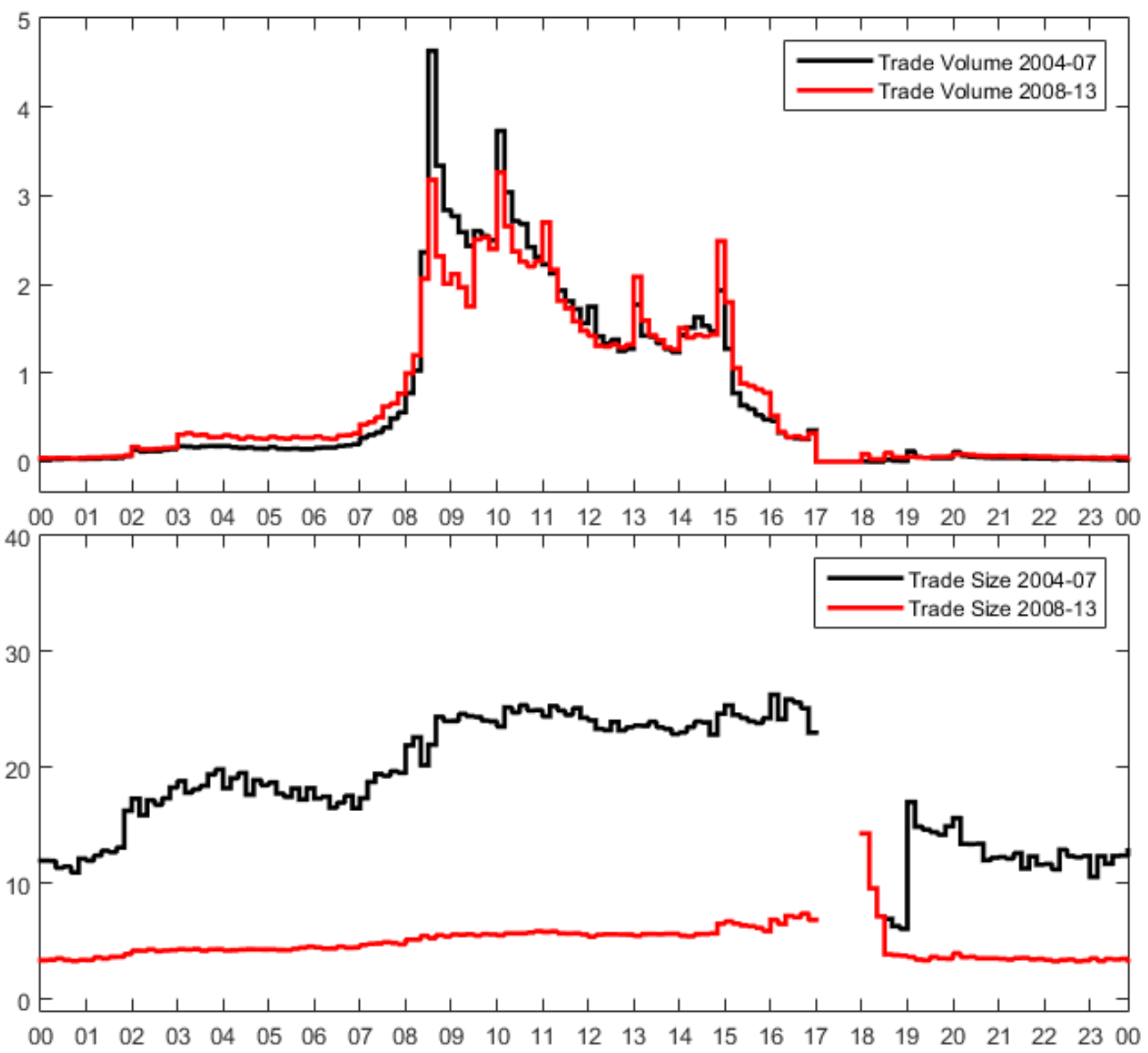


Fig. 5. Intraday Amihud Illiquidity and Weighted Price Contributions of the ECN

The figure shows the mean Amihud illiquidity measures and weighted price contributions for 10-minutelong intervals across the trading day for two time intervals: from 2004 to 2007 and from 2008 to 2013.
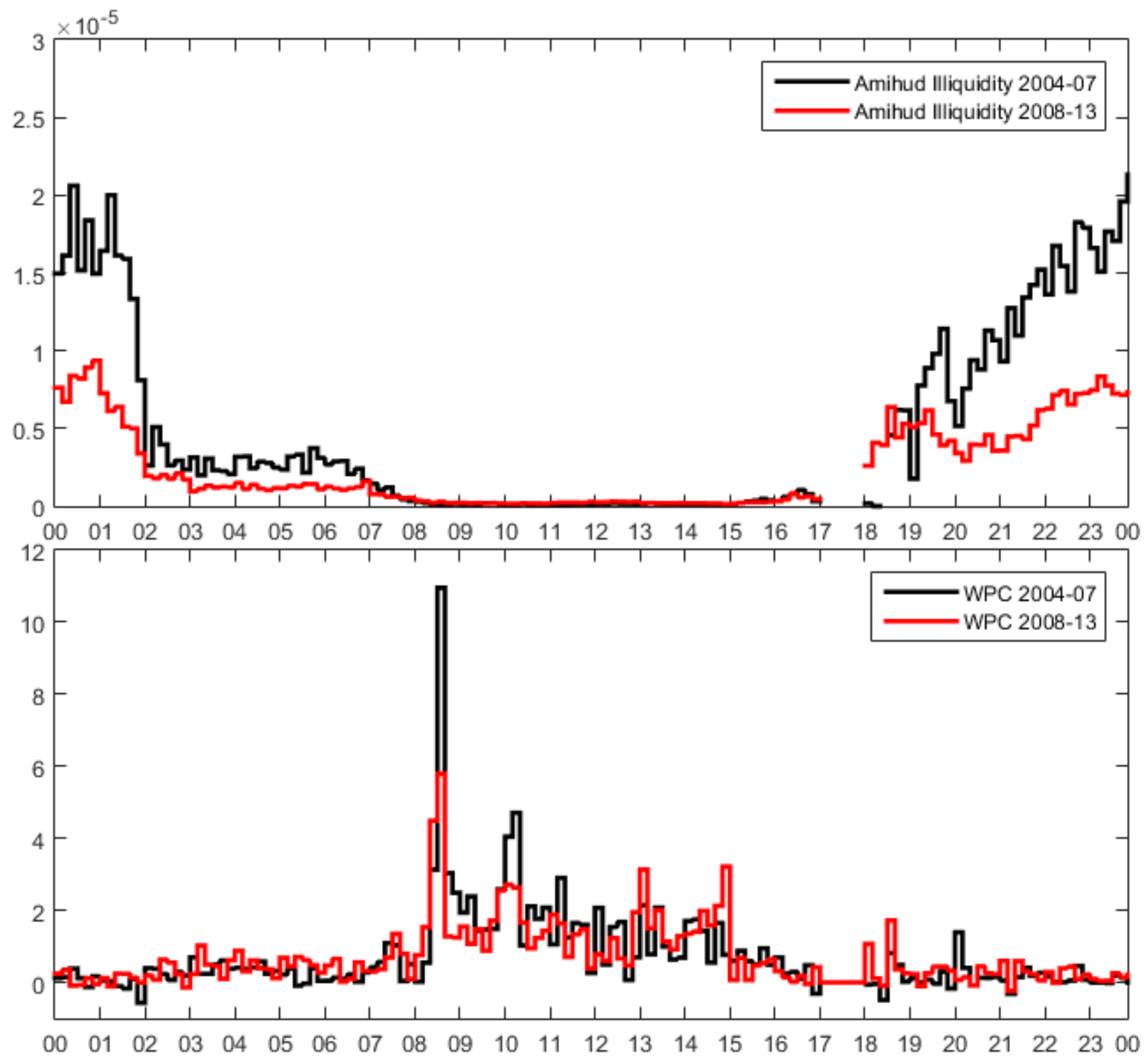
Fig. 6. Trade Volume Figures and Public Innovation Variance Estimates

The figure shows, from top to bottom, the intraday variation in trade volume and the estimates of the public innovation variance $\sigma_{t}^{2}$ from the model presented in section 2.3 for 20 half-yearly intervals from 2004 to 2013. Both the estimations and the trade volumes use data sampled at 5-minutes frequency.
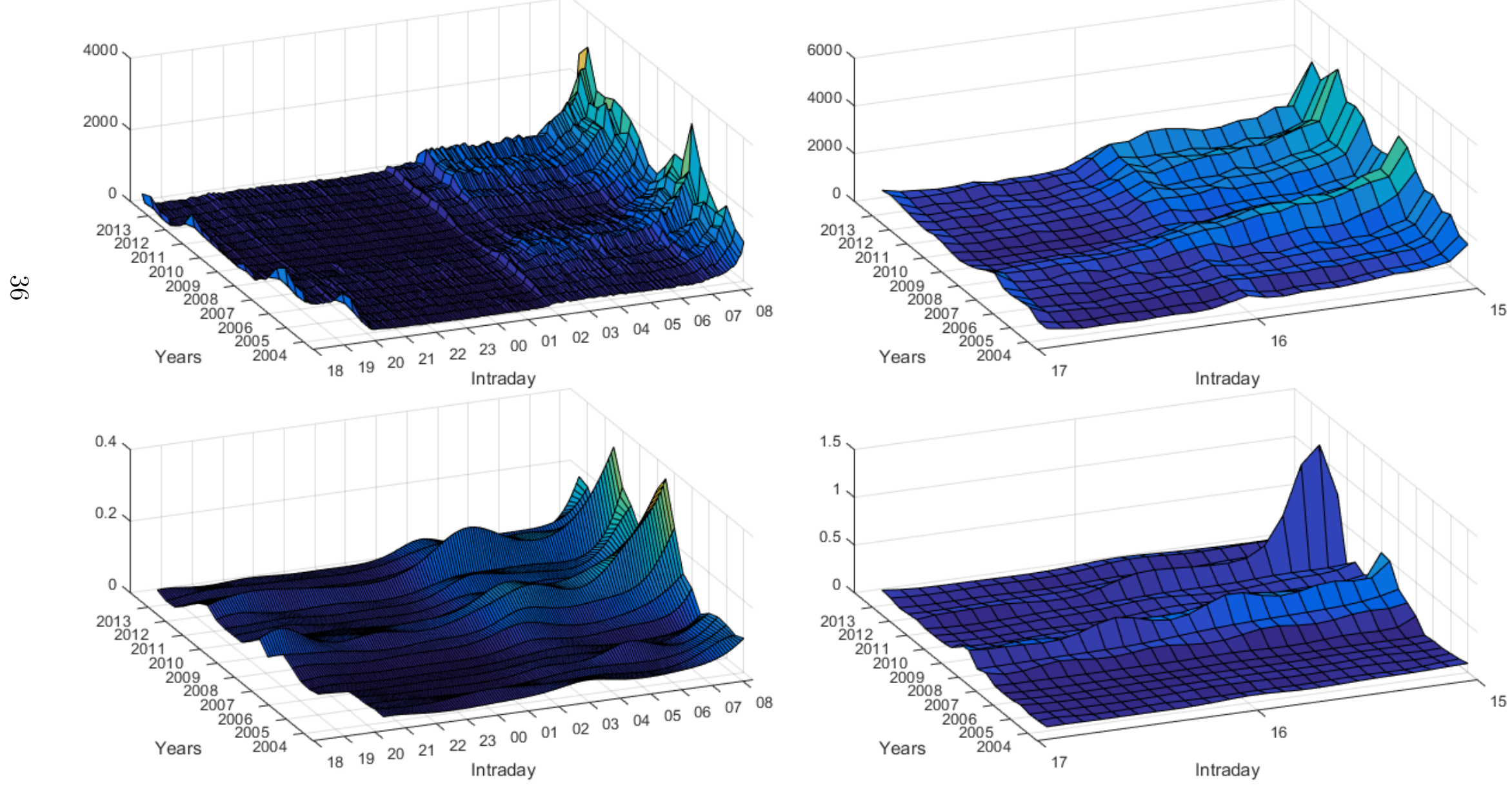
Fig. 7. Information Asymmetry, Price Impact and Noise Variance Estimates

The figure shows, from top to bottom, the estimates of the information asymmetry coefficient $\theta_{t}$ and price impact coefficient $\delta_{t}$ and the noise variance $\omega_{t}^{2}$ from the model presented in section 2.3 for 20 half-yearly intervals from 2004 to 2013 . Both the estimations use data sampled at 5-minutes frequency.
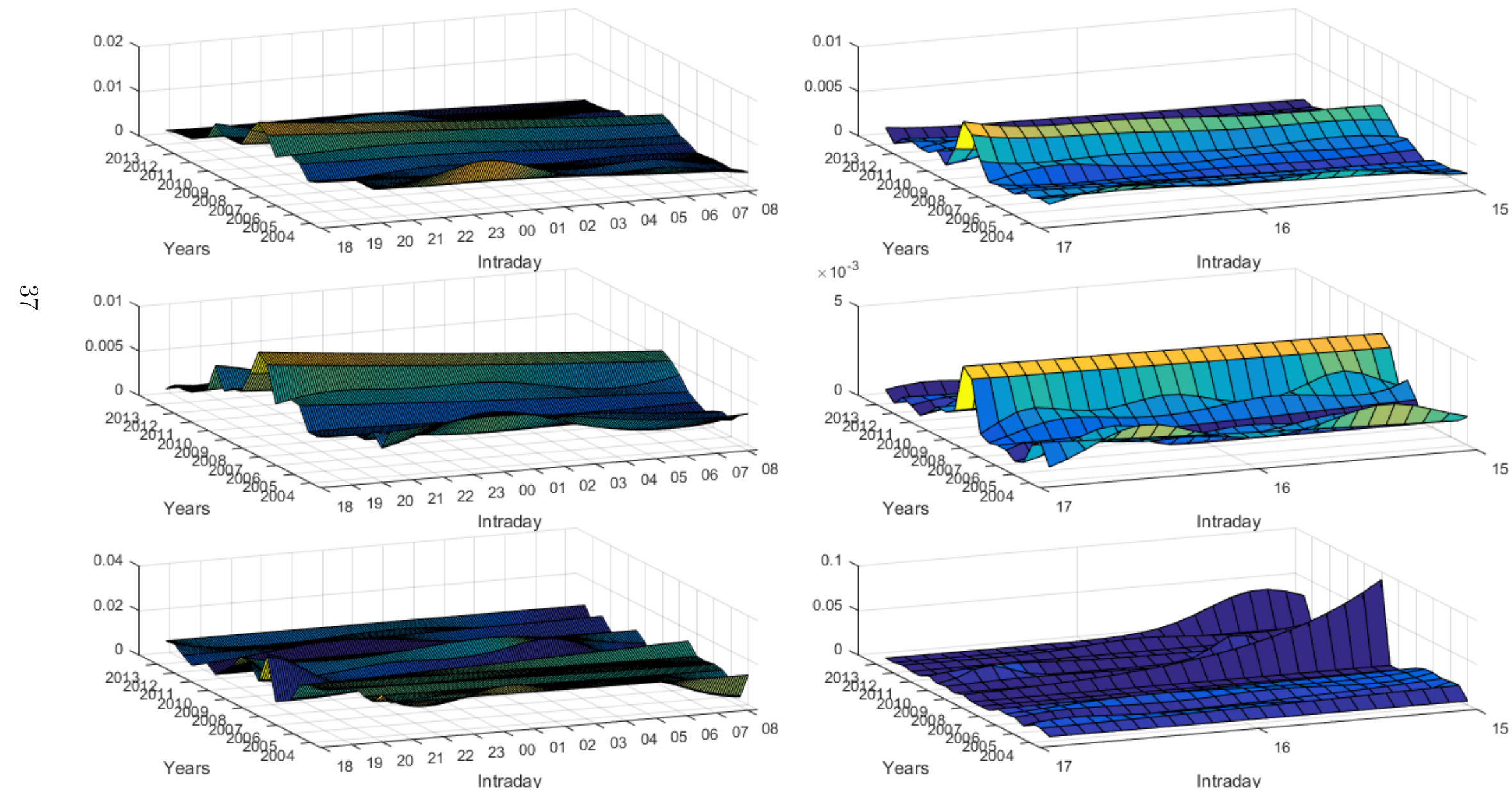
Fig. 8. Noise-to-Innovation Ratios During Afterhours Periods

The figure shows the mean noise-to-innovation ratios in four afterhours periods. The ratios are computed by dividing the noise variance $\omega_{t}^{2}$ to the innovation variance $\sigma_{t}^{2}$ and taking their averages for each afterhours period. The parameters are estimated using the model presented in section 2.3 for 20 half-yearly intervals from 2004 to 2013.

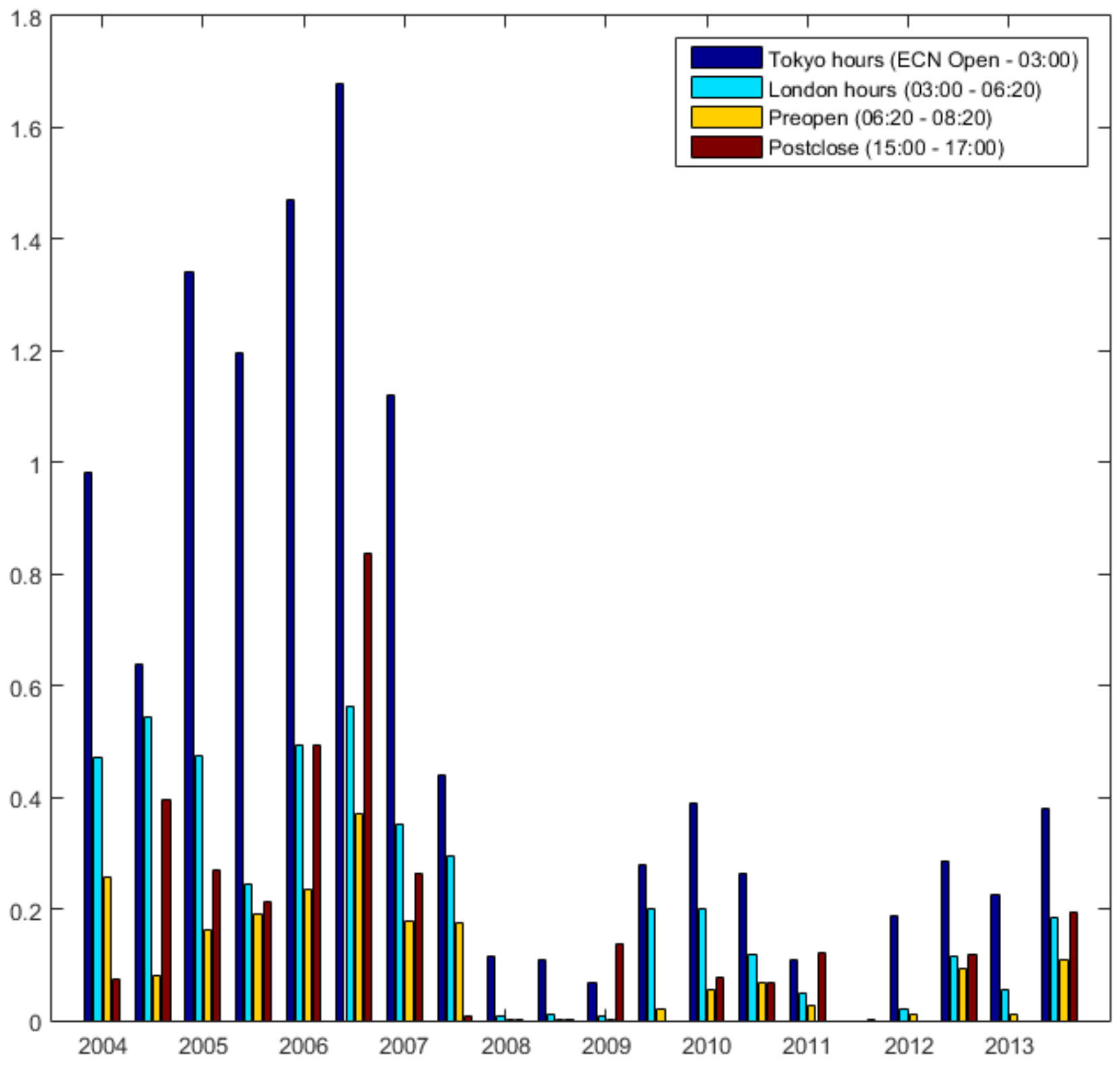


Fig. 9. The Magnitudes of Unexpected Order Flow Coefficients During Afterhours Periods

The figure shows the mean of the unexpected order flow coefficient $\theta_{t}$ in four afterhours periods. The parameters are estimated using the model presented in section 2.3 for 20 half-yearly intervals from 2004 to 2013.

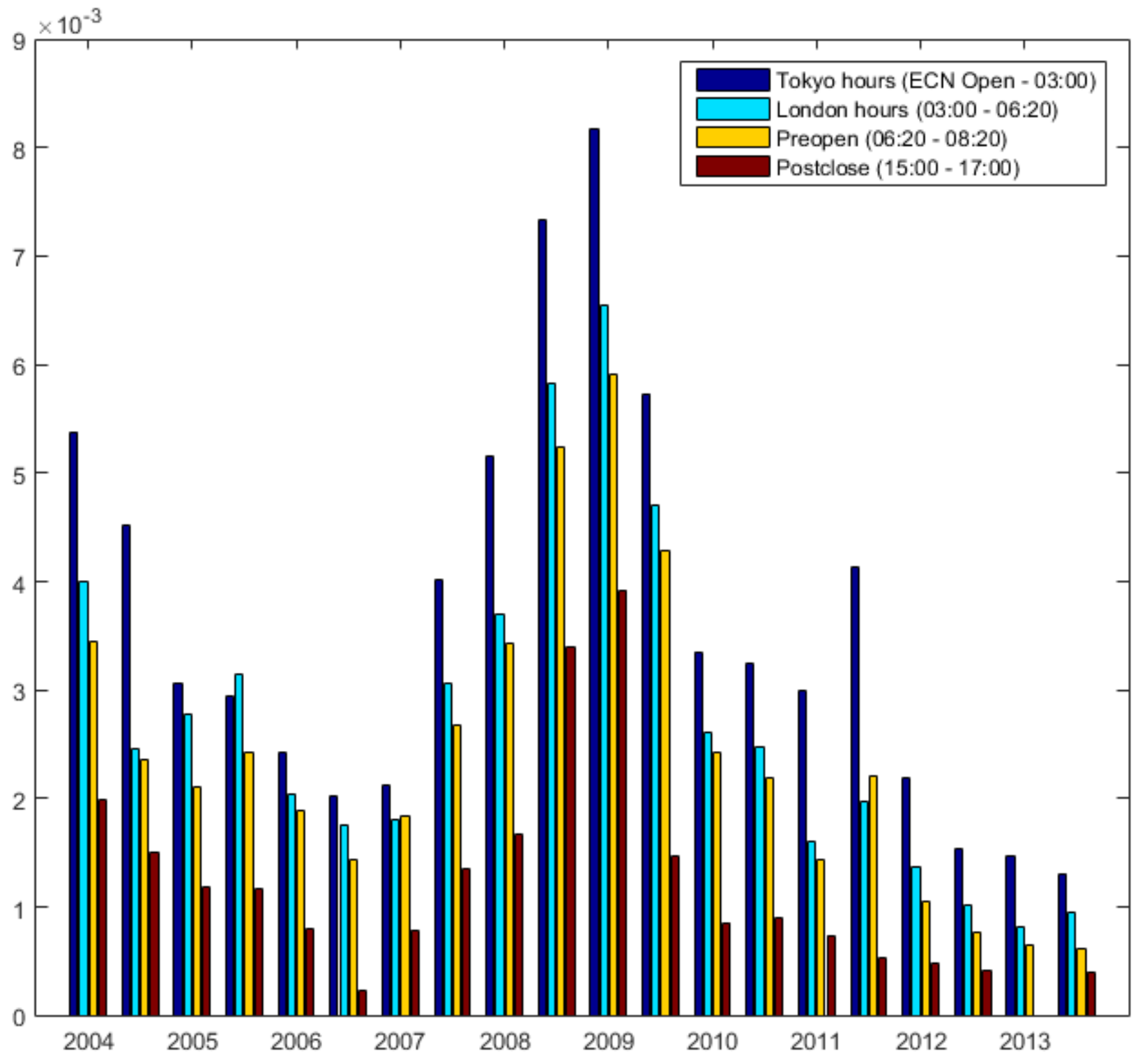


Fig. 10. The Magnitudes of Price Impact Coefficients During Afterhours Periods

The figure shows the mean of the price impact coefficient $\delta_{t}$ in four afterhours periods. The parameters are estimated using the model presented in section 2.3 for 20 half-yearly intervals from 2004 to 2013.

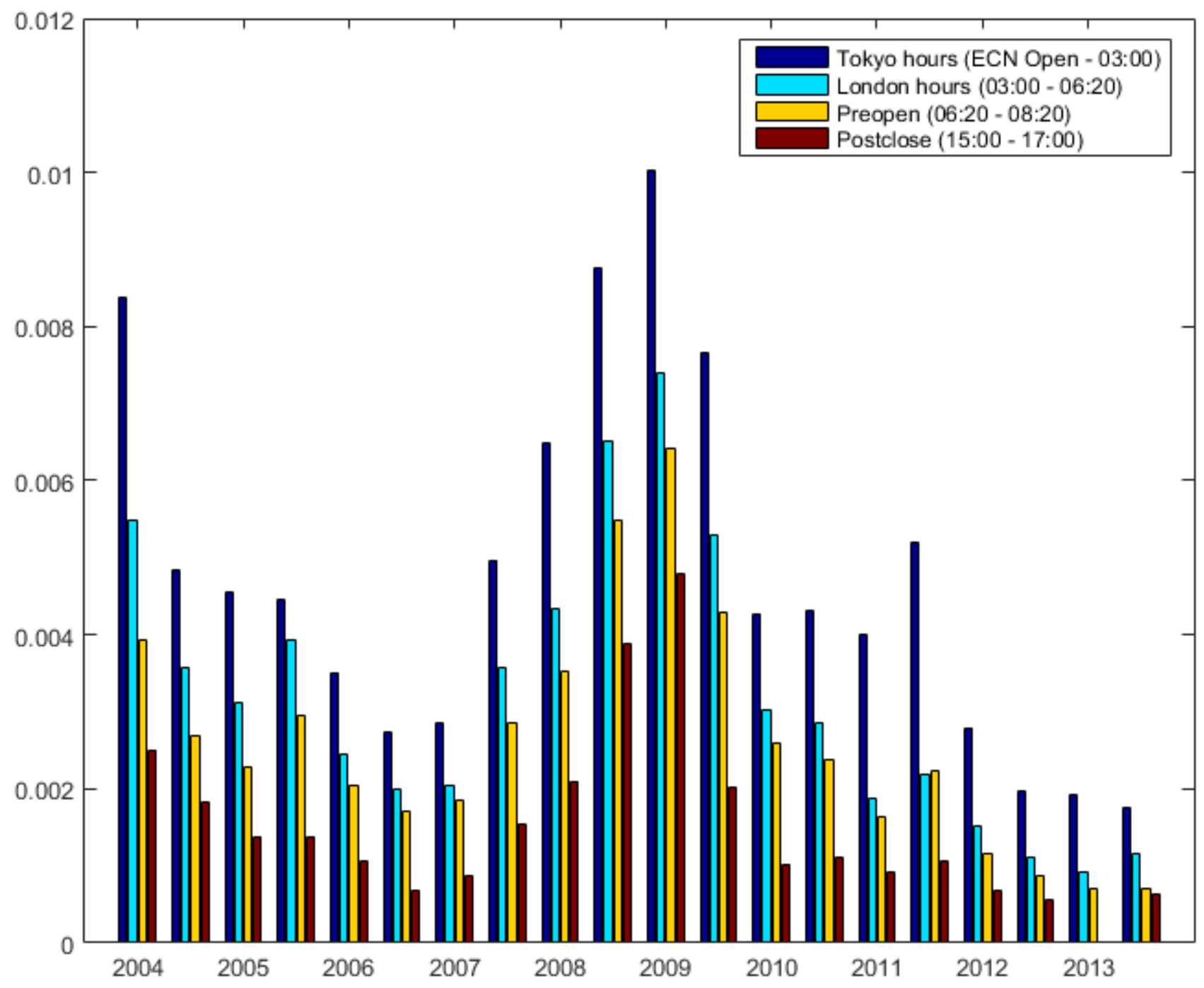


Fig. 11. The Coefficient Estimates for the Cross-Sectional Regressions

The figure shows the coefficient estimates generated by regressing the changes in trade volume on the estimates of public innovation variance, unexpected order flow coefficient and price impact coefficients for each 5-minute interval during the afterhours. Results significant at $5 \%$ level are emboldened. As the regressors are estimates themselves, we use the Murphy and Topel (1985) method to calculate correct standard errors.
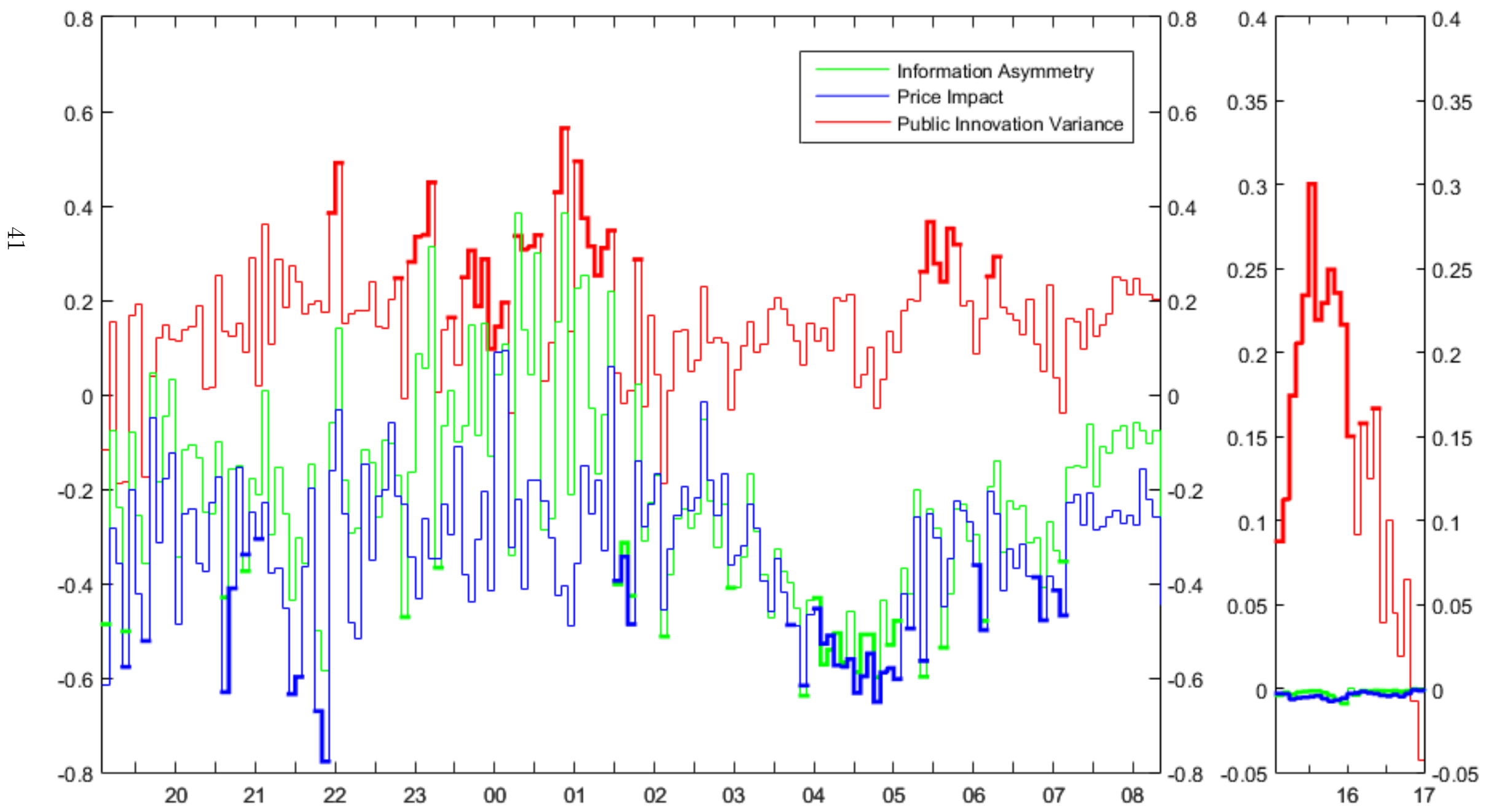